\title{
Evaluation of two spectral wave models for wave hindcasting in the Mackenzie Delta
}

\author{
Md. Azharul Hoque ${ }^{1 *}$, William Perrie ${ }^{2}$, Steven M. Solomon ${ }^{1}$ \\ ${ }^{1}$ Natural Resources Canada, Bedford Institute of Oceanography \\ Dartmouth, Nova Scotia, B2Y 4A2, Canada. \\ ${ }^{2}$ Fisheries and Ocean Canada, Bedford Institute of Oceanography \\ Dartmouth, Nova Scotia, B2Y 4A2, Canada. \\ Email: William.Perrie@dfo-mpo.gc.ca
}

*Corresponding author, present address:

Public Services and Procurement Canada

1713 Bedford Row, Halifax, Nova Scotia, B3J 3C9, Canada

Tel: 1-902-412-7727; Email: azharulhoq@hotmail.com 


\begin{abstract}
Climate change, reduced sea ice and increased ice-free waters over extended areas for longer summer periods potentially lead to increased wave energy in the Beaufort Sea [1, 2], which is a major concern for coastal and offshore engineering activities. We compare two spectral wave models SWAN (Simulating WAves Nearshore) and MIKE 21 SW (hereafter MIKE21) in simulations of storm-generated waves in the Mackenzie Delta region of the southern Beaufort Sea. SWAN model simulations are performed using two nested grids system, whereas MIKE21 uses an unstructured grid system. Forcing fields are defined by hourly hindcast winds. Moving ice edge boundaries are incorporated during storm simulations. Modelled wave spectra from four storms are shown to compare well with field observations. Two established whitecapping formulations in SWAN are investigated: one dependent on mean spectral wave steepness, and the other on local spectral steepness. For the Beaufort Sea study area, we suggest that SWAN wave simulations using the latter local spectral steepness formulation are better than those using the former mean spectral steepness formulation. MIKE21 simulations also tend to agree with SWAN results using the latter whitecapping formulation.
\end{abstract}

Keywords: Arctic, Beaufort Sea, Mackenzie delta, wind waves, MIKE 21, SWAN.

\title{
1. INTRODUCTION
}

Predicting waves in the Arctic environment is an important topic because of related factors such as reduced sea ice extent, increasingly longer open water seasons, sea-level rise and potentially increased storm activity resulting from climate change. Khon et al. [2] suggest that waves in the Arctic Ocean pose a new practical research problem because this ocean has been largely ice covered with no essential wave activity until relatively recently. They also suggested that significant wave heights and extremes will increase due to reductions in sea-ice and regional wind intensification. The risk due to increased waves and associated storm surges and coastal erosion is likely to increase $[3,4,5]$. The Beaufort Sea 
and its coastal region are the focus of considerable interest because of native land claims, archaeology, and potential oil and gas development. A correct assessment of the wave climate in the Beaufort Sea is needed in order to plan infrastructure development and contingency plans for the maintenance of existing structures and sites of cultural importance. Although climate statistics suggest that the frequency and intensity of storms occurring in the Beaufort Sea, and their large year-to-year variability, are not rapidly changing [6], there are difficulties in properly assessing the wave climate. These include the highly variable and complex nature of sea ice which exerts a significant influence over wave fields, as well as the relative scarcity of meteorological and sea state data. Wave hindcasting skill in the Beaufort Sea and Arctic region largely depends on having reliable marine wind fields, accurate simulations of sea ice cover and properties, and accurate bathymetry data.

Improvements in our understanding of hydrodynamics and sediment mobility in coastal waters require high resolution wave models in order to analyse the nearshore shallow water wave conditions and ocean processes. Third generation wave models solve the spectral action balance equation without prior assumptions about the wave spectral shape. SWAN (Simulating WAves Nearshore) and MIKE 21 SW (hereafter, MIKE21) are two widely used, well-tested spectral wave models for nearshore simulations. Both models represent the generation, propagation and dissipation of waves and include the effects of refraction, shoaling and blocking on wave propagation, accounting for wave dissipation by whitecapping, wave-wave interactions, bottom friction and depth-induced wave breaking. Moeini and Etemad-Shahidi [7] compared the performance of SWAN and MIKE21 for wave hindcasting in Lake Erie with wind forcing varying in time but constant in space over the study domain. They found that SWAN outperforms MIKE21 in simulating Hs (significant wave height) while MIKE21 performs better than SWAN in simulating Tp (peak period) and they suggest that the difference in model skills is mainly due to the wind input parameterization. In a wave hindcasting study in the southern Beaufort Sea with the SWAN model, the authors [8] also found that simulations of Hs are relatively good compared to those for Tp. The authors considered the contributions of bottom friction and triad interactions on shallow water wave predictions in the Beaufort Sea area, which is the 
focus region of this study. It is therefore important to further evaluate model sensitivity to local effects in predicting storm-generated waves in this shallow water region.

The main objective of this study is to provide an evaluation of the SWAN and MIKE21 spectral wave models in hindcasting waves in the southern Beaufort Sea. Our specific objectives are: (i) to test the models in shallow southern Beaufort Sea waters for selected storms; and (ii) to evaluate model sensitivity to account for important local effects in predicting nearshore waves in the Mackenzie Delta area. Section 2 briefly describes the study area. SWAN and MIKE21 models are described in Section 3. Model set-ups including bathymetry, grid arrangement, boundary inputs and forcing conditions are discussed in Section 4. Section 5 compares model simulation results with available field observations. Section 6 provides concluding remarks.

\section{STUDY AREA}

This study covers the Canadian Beaufort Sea (Fig. 1) which is bordered to the east and south by Canada and to the southwest by Alaska. The Beaufort Sea is a southward extension of the Arctic Ocean and occupies an area of approximately $450,000 \mathrm{~km}^{2}$. The continental shelf slopes gently to a shelf break located at about $80 \mathrm{~m}$ water depth [9]. The shelf is relatively narrow, ranging in width from $40 \mathrm{~km}$ at parts of this region, to over 150 $\mathrm{km}$ to the north of the Mackenzie delta. Much of the Beaufort Sea is permanently covered by the polar ice pack. However, there is a portion in the south that is seasonally ice-free, typically from late June until mid-October. During this period, storms have a significant impact because the expanse of open water is maximal. Thus, the largest waves and highest storm surges of the season tend to occur in the late summer or early fall, just before the Beaufort Sea freezes over [6]. Local factors such as the topography, coastal effects, and the freeze-up of the Beaufort Sea have a significant effect on the evolution of these systems. Storm winds, which become increasingly frequent in the late August and September, come predominantly out of the west and northwest and occur during the period of greatest open water extent and prior to the initialization of freeze-up [10]. Manson and Solomon [11] suggested possible changes in the seasonal forcing from a current maximum during August 
to September to a maximum during September to October, by 2040, and ever later, October to November, by 2100, when maximum storm surge frequencies, north-westerly wind storm frequencies, open water extend and thawing of ice-bounded sediment coincide.

\section{MODEL DESCRIPTIONS}

\subsection{SWAN Model}

The SWAN model [12] is based on the spectral action balance equation rather than the spectral energy balance equation. The evolution of the action density $N$ is governed by Komen et al. [13]:

$\frac{\partial N}{\partial t}+\nabla_{\vec{x}} \cdot\left[\left(\vec{c}_{g}+\vec{U}\right) N\right]+\frac{\partial c_{\theta} N}{\partial \theta}+\frac{\partial c_{\sigma} N}{\partial \sigma}=\frac{S_{t o t}}{\sigma}$

where, $N(\sigma, \theta)$ is the action density spectrum, $x$ is space, $t$ is time, $\theta$ is wave direction, $\sigma$ is relative frequency, $S_{\text {tot }}$ is the source term total, and $c_{g}$ represents the propagation velocity. The first term in the left hand side of the equation represents the local rate of change of action density in time. The second and third terms represent propagation of $N$ in geographic space, accounting for shoaling as the group velocity $c_{g}$ decreases in shallow water. The fourth term represents depth-induced and current-induced refraction. The fifth term represents shifting of the relative frequency due to variations in depth and currents. Wave propagation, as described by the left-hand side of Equation (1) is balanced by local changes to the wave spectrum due to $S_{t o t}$ on the right-hand side, which may be expressed as:

$S_{t o t}=S_{i n}+S_{w c}+S_{n l 4}+S_{n l 3}+S_{b f}+S_{b r}$

Here, $S_{i n}$ is the generation of energy by wind, $S_{w c}$ is whitecapping dissipation, $S_{n l 4}$ is the nonlinear 4-wave interactions, $S_{n l 3}$ is the nonlinear triad wave-wave interactions, $S_{b f}$ is bottom friction, and $S_{b r}$ is depth-induced wave breaking. The first three source terms are significant in deep water and the last three terms are significant in shallow water. 
A number of alternative whitecapping expressions have been proposed in SWAN to improve model accuracy as mentioned by Komen et al. [13] and Holthuijsen [15]. In this study, two whitecapping formulations are used to evaluate SWAN model sensitivity in the Mackenzie Delta. One is based on the mean spectral steepness following Komen et al. [13] and the other one is based on local spectral steepness following Van der Westhuysen et al. [16]. The whitecapping formulation by Komen et al. [13] is based on whitecapping processes represented by the pulse-based model of Hasselmann [14] which may be expressed as:

$$
S_{w c}(\sigma, \theta)=-C_{d s}\left(\frac{k}{\tilde{\mathrm{k}}}\right)^{q}\left(\frac{\tilde{s}}{\tilde{\mathrm{S}}_{\mathrm{PM}}}\right)^{r} \tilde{\sigma} E(\sigma, \theta)
$$

where $k$ is the wave number, $\tilde{k}$ is the spectral mean wave number, $\widetilde{\sigma}$ is the spectral mean radian frequency and $\tilde{S}$ is the mean spectral steepness. The mean steepness $\tilde{S}$ is defined as $\tilde{k} \sqrt{E_{t o t}}$, where $E_{t o t}$ is the total spectral variance. $\tilde{S}_{P M}$ is the mean steepness of the PiersonMoskowitz spectrum. The turning parameters of this expression are $C_{d s}, q$ and $r$ which are set to the default values in SWAN, in this study, as follows: $C_{d s}=2.36 \times 10^{-5}, q=1, r=4$.

The Van der Westhuysen et al. [16] formulation is a saturation - based whitecapping dissipation expression adapted from the expression of Alves and Banner [16]. The latter is based on an apparent relationship between wave groups and whitecapping dissipation. This adaptation makes applications possible to mixed sea-swell conditions and to shallow water conditions. Moreover, the original expression of Alves and Banner [16] was simplified by removing the (previous) dependencies on mean spectral steepness and wavenumber in the original expression. Thus, the whitecapping source term of this formulation is expressed as:

$$
S_{w c}(\sigma, \theta)=-C_{d s}\left[\frac{B(k)}{B_{r}}\right]^{p / 2} \sqrt{g k} E(\sigma, \theta)
$$

which is dependent on local wave number $k$ and independent of mean spectral steepness. Whitecapping occurs when $B(k)>B_{r}$, where $B_{r}$ is the saturation threshold, and spectral saturation is $B(k)$, which is defined in terms of wave number as: 


$$
B(k)=\int_{0}^{2 \pi} \frac{d \sigma}{d k} k^{3} E(\sigma, \theta) d \theta=C_{g} k^{3} E(\sigma)
$$

Exponent $p$ has a functional form that is set to a constant $p_{0}$, when $B(k)>B_{r}$. When there is no whitecapping, $B(k)<B_{r}$ and $p$ smoothly transitions to account for other (weaker) forms of dissipation such as turbulence and longwave-shortwave interactions. The SWAN default values for tuneable parameters are $B_{r}=1.75 \times 10^{-3}$ and $C_{d s}=5.0 \times 10^{-5}$.

Transfer of wind energy to waves, denoted $S_{\text {in }}$ in SWAN, is described by different authors [7, 8 and 12]. Bottom friction $\left(S_{b r}\right)$ also has several different formulations: the empirical JONSWAP model of Hasselmann et al. [19], the drag law model of Collins [20] and the eddy viscosity model of Madsen et al. [21]. Energy dissipation due to depthinduced breaking $\left(S_{b r}\right)$ follows Battjes and Jansen [22] whereby the maximum wave height $H_{\max }$ in shallow water depth $d$ is limited by the relation $H_{\max }=\gamma d$, where $\gamma$ is the breaking parameter, assumed to be 0.73 in SWAN. In deep water, quadruplet wave-wave interactions dominate the evolution of the wind wave spectra and are represented by the discrete-interaction approximation (DIA) of Hasselmann et al. [23]. In very shallow water, triad wave-wave interactions are important for depths which are small relative to wave height and wave length; they are parameterized by the lumped triad approximation (LTA) of Eldeberky [24] and Eldeberky and Battjes [25]. The discretization of the action balance equation (Equation 1) in SWAN model is carried out using finite difference schemes in five dimensions: time, geographic space $(x, y)$ and spectral space $(\sigma, \theta)$. The equations are solved numerically via an iterative process.

\subsection{MIKE21 Model}

MIKE21 is a third generation spectral wave model based on unstructured grids. The model includes two different formulations: a directional decoupled parametric formulation and a fully spectral formulation. The former is based on parameterization of the wave action conservation equation, following Holthuijsen et al. [26]. The fully spectral formulation, which is used in this study, is based on the wave action conservation 
Equations (1) and (2), as explained in Komen et al. [13] and Young [27]. In MIKE21, source term formulations for wind input $S_{i n}$, dissipation $S_{w c}$, nonlinear quadruplet wavewave interactions $S_{n l}$ and depth-induced breaking $S_{b r}$ are essentially the same as those described for the SWAN model in the previous section. These terms are also discussed by Komen et al. [13]. There is no explicit representation for triad wave-wave interactions. The dissipation source function for bottom friction used in the spectral wave model version of MIKE21 is based on the quadratic friction law and linear wave kinematic theory. Its proportionality coefficient depends on the hydrodynamic and sediment conditions corresponding to a particular application, as described in Johnson and Kofoed-Hansen [28]. Bottom friction is specified in four possible different ways: (i) a constant friction coefficient $C_{f}$ appropriate for moderate storm conditions, namely the mean JONSWAP value of $0.0077 \mathrm{~m} / \mathrm{s}$ as tested with the WAM model [13]; (ii) a constant friction factor $f_{w}$ whereby the friction coefficient $C_{f}$ is obtained by multiplying the $r m s$ wave orbital velocity value with the friction factor $f_{w}$; (iii) Nikuradse roughness, $k_{N}$, as suggested by Weber [29] in which the friction factor is calculated using the expression of Johnson and Carlsen [30]; and (iv) use of the median sediment size, $D_{50}$. Depth-induced wave breaking is considered based on the bore-based model of Battjes and Janssen [22] and a dissipation source term is used following Eldeberky and Battjes [24].

The discretization in geographical and spectral space is performed using a cellcentered finite volume method. An unstructured grid is used in the geographical domain. The special domain is discretized by subdivision of the continuum into non-overlapping triangular elements. The integration in time is performed using a fractional step approach whereby a multi-sequence explicit method is applied for the propagation of wave action. The source term integration step is performed using an implicit method. 


\section{MODEL SETUP AND ANALYSIS}

\subsection{Computational domain and bathymetry}

The computational domain covers the region of Canadian Beaufort sea bounded by longitudes $142^{\circ} 30^{\prime} \mathrm{W}$ and $126^{\circ} \mathrm{W}$ and latitude $71^{\circ} 45^{\prime} \mathrm{N}$ (Fig. 2). The SWAN model is implemented on a nested grid system consisting of a fine resolution grid nested within a coarse resolution domain. The fine resolution grid covers the Mackenzie delta and adjacent area as shown in Fig. 2. Table 1 describes the details of the grid set-ups used for the SWAN model. ETOPO2 bathymetry with $2^{\prime}$ resolution is used for the coarse grid domain. For the nested grid run, a fine resolution $\left(0.015^{\circ} \times 0.005^{\circ}\right)$ bathymetry is generated based primarily on data from Canadian Hydrographic Service charts and field sheets. The same bathymetric information is used to develop the unstructured mesh (Fig. 3) over the computational domain for MIKE21 simulations.

\section{Table 1}

Computational grid for SWAN simulation: $\Delta_{\lambda}$ and $\Delta_{\varphi}$ are resolutions in longitude $(\lambda)$ and latitude $(\varphi), \mathrm{n} \lambda$ and $\mathrm{n} \varphi$ are the numbers of points in $\lambda$ and $\varphi$, and $\Delta \mathrm{t}$ is time step.

\begin{tabular}{llllllll}
\hline Grid & Longitude, $\lambda$ & Latitude, $\varphi$ & $\Delta_{\lambda}$ & $\Delta_{\varphi}$ & $\mathrm{n} \lambda$ & $\mathrm{n} \varphi$ & $\Delta \mathrm{t}(\mathrm{min})$ \\
\hline Coarse & $-142.5^{\circ} \sim-126^{\mathrm{o}}$ & $68.9^{\circ} \sim 71.75^{\circ}$ & $0.15^{\circ}$ & $0.05^{\mathrm{o}}$ & 111 & 58 & 5 \\
Fine & $-138^{\circ} \sim-133.05^{\circ}$ & $68.9^{\circ}-69.85^{\circ}$ & $0.03^{\circ}$ & $0.01^{\mathrm{o}}$ & 166 & 96 & 5 \\
\hline
\end{tabular}

SWAN model simulations are performed using version 40.51 in a non-stationary two dimensional mode. Time is discretized with a constant time step $\Delta t$ for the simultaneous integration of the propagation terms and the source terms. Computational time steps (Table 1) are selected based on different trial runs of the model in order to find optimal computational time and numerical efficiency. Spectral space is discretized with 36 equally spaced directions $\left(\Delta \theta=10^{\circ}\right)$ and 35 logarithmically spaced frequencies between $f_{\min }=0.04$ $\mathrm{Hz}$ and $f_{\text {max }}=1.0 \mathrm{~Hz}$. 
MIKE21 simulations are conducted using the fully spectral formulation with the standard wave-induced stress parameterization for wind input $S_{\text {in }}$ following Komen et al. [13]. The same set-ups for discretization $(\Delta \theta$ and $\Delta f)$ parameters and coefficients are used as specified for the SWAN simulations. MIKE21 uses a variable time step interval in the time integration of the governing equations whereby the CFL criterion is satisfied for the local time step for each element. Dissipation due to whitecapping, $S_{w c}$, and depth induced wave breaking, $S_{b r}$, are considered in the simulations.

\subsection{Wind fields and modelled storms}

The quality and accuracy of the wind fields are important factors in hindcasting waves. As demonstrated by various authors $[14,31,32,33,34,35]$ wave predictions are very sensitive to wind fields. Murray and Maes [36] suggest that improvements in the winds can provide the single most important contribution towards improving the wave estimates in the Beaufort Sea. A publically available state-of-the-art data set for winds and ice, constructed by the Environment and Climate Change (ECCC) Department of the Government of Canada is used in the present study. This data set is based on the reanalysis by Swail et al. [37] under the Meteorological Service of Canada Beaufort (hereafter denoted as MSCB) project. Swail et al. [37] produced an hourly hindcast for the entire period 1985-2005 at 3442 grid points with resolutions of $0.15 \mathrm{deg}$ in the east-west direction and $0.05 \mathrm{deg}$ in the north-south direction. They analyzed the wind fields using the Interactive Objective Kinematic Analysis (IOKA) system of Oceanweather Inc. (OWI). In the wind analysis, all available measured wind data in the Beaufort region were brought into a background field and assimilated at 6-hourly intervals by an experienced kinematic analyst. The coastal stations measurements of wind speed were transformed to effective 10-m reference elevation, using station surface roughness and anemometer height. The background wind field is taken from the 10-m surface gridded wind products of the NCEP-NCAR reanalysis (NRA). The global QuikSCAT wind database http://manati.star.nesdis.noaa.gov/ products/QuikSCAT.php) was used to identify and correct systematic errors in the NRA winds within the domain of the wave models. Detail 
comparisons and statistics are reported by Swail et al. (2007) showing that the MSCB reanalysis winds compare well with available buoy winds.

Storms for model simulations in this study are selected for time periods when in-situ wave measurements are available for model comparisons. During the early 1980s, wave data were collected by oil companies and the Department of Fisheries and Ocean Canada (DFO) during the ice-free period in the Beaufort Sea. The data have been archived by the Integrated Science Data Management (ISDM) service of DFO (formerly the Marine Environmental Data Service) and are available at http://www.meds-sdmm.dfompo.gc.ca/isdm-gdsi/index-eng.html. Although much of the ISDM data were obtained prior to the MSCB hindcast period (1985-2005), there are three periods when wave measurements are available in the study area. These three wave measurement locations are WELL116, MEDS265, and MEDS291 mentioned in Table 2. An additional set of wave measurements were provided by H. Melling (Institute of Ocean Sciences, Sidney, British Columbia, Canada) for a storm in 2004 (BMH04). The locations of these four available wave measurement stations are shown in Fig. 2. These measurement stations include a very shallow region (WELL116) as well as a deeper offshore location BMH04.

\section{Table 2}

Wave observation stations in the study area during 1985-2005.

\begin{tabular}{lllll}
\hline Observation Station & $\begin{array}{l}\text { Longitude } \\
(\mathrm{deg})\end{array}$ & $\begin{array}{l}\text { Latitude } \\
(\mathrm{deg})\end{array}$ & $\begin{array}{l}\text { Still water } \\
\text { depth }(\mathrm{m})\end{array}$ & $\begin{array}{l}\text { Year of } \\
\text { Observation }\end{array}$ \\
\hline WELL 116 & -135.87 & 69.48 & 2.24 & 1985 \\
MEDS 291 & -134.6 & 69.81 & 7.0 & 1991 \\
MEDS 265 & -133.66 & 70.07 & 33.0 & 1987 \\
BMH04 & -129.762 & 70.896 & 33.0 & 2004 \\
\hline
\end{tabular}

The storms events considered in this study are shown in Table 3, coinciding with these four measurements years, so that model predictions can be compared with wave observations. In the case of BMH04, the model run is continued beyond the actual storm event in order to examine model predictions in decaying wave conditions. Figure 4 
illustrates the comparisons of MSCB modelled wind speed and direction (oriented from north) data with field measurements at Tuktoyaktuk $(133 \mathrm{~W}, 69.45 \mathrm{~N})$ during the four storms used in this study.

\section{Table 3}

Storm events selected for model simulations.

\begin{tabular}{lll}
\hline Year & Date & Maximum wind speed $(\mathrm{m} / \mathrm{s})$ \\
\hline 1985 & $16-18$ Sept & 17.11 \\
1987 & $27-29$ Aug & 14.18 \\
1991 & $04-06$ Aug & 13.28 \\
2004 & $13-16$ Aug & 12.42 \\
\hline
\end{tabular}

\subsection{Ice edges}

Ice cover data from the MSCB ice edge analysis are used to specify the moving boundary of the ice edge in the wave models during the storms that were selected for this study. In the MSCB ice edge analysis Swail et al. [37] updated the ice edge on a weekly basis to allow the best possible representation of changing ice conditions during the storm periods. In fact, the Canadian Ice Service (CIS) also provides high-resolution ice concentration data on a weekly basis; these data were binned and averaged for the MSCB ice edges analysis by Swail et al. [37]. They also did comparisons of their ice edge analysis that included the CIS data in Canadian waters and GFSC/DMSP ice data in other areas to complete the ice edge field across the entire coarse grid domain. A blend of the two ice sources was required since the CIS data did not cover the entire domain of the $28 \mathrm{~km}$ model grid used by Swail et al. [37].

Studies on the marginal ice zone and its effect on wave damping have found that $50 \%$ ice concentration will dampen out essential all waves with periods less than $10 \mathrm{~s}$, for waves generated in open water and propagating into the pack ice [38]. Eid and Cardone [39] and Perrie and $\mathrm{Hu}[40,41]$ suggest that $50 \%$ ice concentration is probably a good definition of 
the ice edge for the purpose of wave generation. At this concentration the ice cover is sufficient to prevent wave generation and to dampen short period waves. In the present simulation, the moving ice edge during a given storm is specified, based on $50 \%$ ice concentration. During each storm simulation, grid points with greater than $50 \%$ ice are considered as land points with no wave generation or propagation. Among the four selected storms, the 1987 storm was ice free. During the 2004 storm there were some scattered ice cover areas along the north-eastern and north-western boundaries of the domain; based on preliminary model test runs this boundary and these ice cover areas do not have any influence on waves in the Mackenzie delta. Ice cover during storms 1985 and 1991 storm durations are shown in Fig. 5 and are incorporated in the model simulations.

\subsection{Water level and tidal current}

Water levels measured at Tuktoyaktuk are used as model inputs for wind set-up. With a relatively small tidal range $(0.3 \mathrm{~m}$ average and $0.5 \mathrm{~m}$ for large tides $)$ and shallow basin over a wide area, the southern Beaufort basin is subject tidal currents that are considered to be too small [42] to produce significant wave refraction effects and are therefore ignored in the model simulations.

\subsection{Statistical analysis}

Statistical comparisons between model simulations and field observations are made using bias, root-mean-square error (RMSE), standard deviation of error (STDE), scatter index $(S I)$, and Pearson's correlation coefficient $(r)$. If $x_{c}$ represents model estimates, $x_{o}$ represent field observations and $n$ is the number of data, these statistical parameters can be expressed as:

$$
\begin{aligned}
& \text { Mean: } \overline{x_{c}}=\frac{1}{n} \sum_{i=1}^{n} x_{c}, \overline{x_{o}}=\frac{1}{n} \sum_{i=1}^{n} x_{o} \\
& \text { Bias }=\overline{x_{c}}-\overline{x_{o}}
\end{aligned}
$$




$$
\begin{aligned}
& R M S E=\sqrt{\frac{1}{n} \sum_{i=1}^{n}\left(x_{c}-x_{o}\right)^{2}} \\
& S I=R M S E / \sqrt{\overline{x_{c} x_{o}}} \\
& r=\frac{\sum_{i=1}^{n}\left(x_{c}-\overline{x_{c}}\right)\left(x_{o}-\overline{x_{o}}\right)}{\sqrt{\sum_{i=1}^{n}\left(x_{c}-\overline{x_{c}}\right)^{2} \sum_{i=1}^{n}\left(x_{o}-\overline{x_{o}}\right)^{2}}}
\end{aligned}
$$

\section{RESULTS AND DISCUSSION}

\subsection{WELL116 (2.24 m water depth) during 1985 storm}

SWAN model comparisons with observations by Hoque et al. [8] in the same study area show that model simulations at WELL116 during the 1985 storm are in good agreement with field measurement when bottom friction and triad interactions are disregarded. Based on trial calculations in shallow water, MIKE21 simulations are also found to provide good wave simulations, disregarding these two shallow water physics formulations, as in SWAN. Therefore, in this study we do not consider bottom friction or triad interactions. The finite depth effect is taken into account in both the models through the depth-induced wave breaking parameters $S_{b r}$. Model simulations with and without ice cover (shown in Figure 5) during this storm do not show any essential difference in Hs and Tp at WELL116. This is essentially because the north-western portion of the computational domain was ice free during the storm and the waves were from the northwest. Moreover, as the water depth this location is very shallow, the waves were mainly governed by finite depth effects.

The comparisons between predicted and observed wave parameters at WEL116 are illustrated in Table 4 and Fig. 6. A focal point for comparisons is the alternative whitecapping expressions that have been proposed; one based on the mean spectral steepness, following Komen et al. [43], and the other, due to Van der Westhuysen et al. [16], depending on local spectral steepness. These formulations are hereafter denoted as the 
Komen and Westhuysen formulations, respectively. When Komen and Westhuysen formulations are used, there are no evident differences in SWAN simulations in estimates of Hs; however the Westhuysen formulation gives a better prediction of Tp values than the Komen formulation. By comparison, MIKE21 over-predicts Hs compared to SWAN simulations or observed data. It can also be seen that Tp is better simulated by MIKE21 than the SWAN simulations (Fig. 6, Table 4). Moeini and Etemad-Shahidi [7] also reported a similar finding in their study comparing SWAN and MIKE21 simulations in Lake Erie.

\section{Table 4}

Statistical analysis of wave parameters at WELL116 during the 1985 storm

\begin{tabular}{llllllll}
\hline & & $\overline{x_{c}}$ & $\overline{x_{o}}$ & BIAS & RMSE & SI & $\mathrm{R}$ \\
\hline Hs & SWAN (Komen) & 1.256 & 1.243 & 0.013 & 0.144 & 0.12 & 0.81 \\
& SWAN (Westhuysen) & 1.264 & 1.243 & 0.021 & 0.143 & 0.11 & 0.82 \\
& MIKE21 & 1.411 & 1.243 & 0.168 & 0.215 & 0.16 & 0.83 \\
\multirow{3}{*}{ Tp } & SWAN (Komen) & 8.258 & 9.002 & -0.744 & 1.138 & 0.13 & 0.74 \\
& SWAN (Westhuysen) & 9.142 & 9.002 & 0.14 & 0.8 & 0.09 & 0.78 \\
& MIKE21 & 8.874 & 9.002 & -0.128 & 0.669 & 0.07 & 0.82 \\
\hline
\end{tabular}

Table 4 shows that although the MIKE21 simulations of Hs give relatively high bias, RMSE and SI values, whereas the related correlation coefficient, $R$, is slightly better than those of the SWAN simulations. The R-value is very sensitive to higher deviations from the mean, while bias and RMSE are more sensitive to larger errors between observed and modelled values. This is evident in the comparisons: Figure 6 shows that the observed data have higher variability than the model data. Because the bias (Equation 7) is the difference between the mean of calculated values and corresponding observed data, variability of the observed data per se, does not increase the bias, but does increase the RMSE and SI, following Equations 8 and 9. However, the overall values for RMSE and SI in the WELL 116 simulation are very low compared to those of other storms used in this study. The MIKE21 simulation for Tp gives a higher correlation coefficient, $\mathrm{R}$, and lower values for RMSE and SI than those of the SWAN simulations. 
The model sensitivities are also evaluated based on variance spectra as shown in Fig. 7. The variance spectra at the peak of the 1985 storm show that MIKE21 over- predicts the spectral peak whereas the SWAN simulations under-predict the peak. The MIKE21 simulation also tends to suggest a wider spectral band. Thus, MIKE21 results in an overestimate in Hs values. Part of this overestimate in spectral variance is due to the spatial discretization in the unstructured MIKE21 grid which has a water depth of $2.5 \mathrm{~m}$ whereas the water depth obtained in structured grid SWAN simulations is $2.24 \mathrm{~m}$. Although the forward face $f<f_{p}$ (where $f_{p}$ is the peak frequency) of the spectrum in the MIKE21 simulation is biased toward low frequency energy, the corresponding Tp values are close to those obtained by the SWAN simulation using the Westhuysen dissipation formulation.

\subsection{MEDS291 (7 m water depth) during the 1991 storm}

Model simulations are found to be in better agreement with field measurement when bottom friction and triad interactions are disregarded. In these cases, finite depth effects are included in the simulations through depth-induced breaking. The presence of the ice edge does not have any essential effects on simulated waves at MEDS291. This result is obtained because the shallow water processes are dominant in determining the growth and development of the wave heights at this location. Moreover, the distance to the ice edge area is relatively large and the waves propagate from directions that do not produce any wave-ice effects, at this location. Comparisons of model results with data for the 1991 storm are shown in Fig. 8. In this case, both the MIKE21 and SWAN simulations underpredict Hs and Tp during the growing stage of the storm, and over-predict these parameters during the peak of the storm. Table 5 indicates that the SWAN simulations are better than the MIKE21 simulation in terms of statistical measures. The Tp simulations are slightly better than the simulations of Hs.

As shown in Fig. 8, model simulations by both SWAN and MIKE21 are quite comparable during the growing phase of the storm. However, the storm peak MIKE21 over-predicts both Hs and Tp whereas the SWAN simulations (using either Komen or Westhyusen formulations for dissipation) are in relatively good agreement with field 
observations. Thus, the statistical analysis in Table 5 suggests that the MIKE21 simulation shows poor correlation coefficients, R, compared to the SWAN simulations.

\section{Table 5}

Statistical results for wave parameters at MEDS 291 during the 1991 storm.

\begin{tabular}{llllllll}
\hline & & $\overline{x_{c}}$ & $\overline{x_{o}}$ & BIAS & RMSE & SI & $\mathrm{R}$ \\
\hline Hs (m) & SWAN (Komen) & 0.938 & 0.955 & -.017 & 0.380 & 0.40 & 0.75 \\
& SWAN (Westhuysen) & 1.001 & 0.955 & 0.046 & 0.431 & 0.44 & 0.74 \\
& MIKE21 & 1.138 & 0.955 & 0.183 & 0.518 & 0.50 & 0.59 \\
\multirow{3}{*}{ Tp (sec) } & SWAN (Komen) & 4.149 & 4.206 & -0.057 & 0.820 & 0.20 & 0.78 \\
& SWAN (Westhuysen) & 4.149 & 4.206 & -0.057 & 0.820 & 0.20 & 0.78 \\
& MIKE21 & 4.932 & 4.206 & 0.726 & 1.409 & 0.31 & 0.47 \\
\hline
\end{tabular}

The modelled variance spectra suggest that in the case of high wave energy situations (as shown in the top two panels of Fig. 9) the spectral peaks are better simulated by MIKE21, or with the SWAN model with the Westhuysen dissipation formulation, than that resulting from the Komen dissipation. Spectral forward faces (represented by $f_{p}<f$ ) simulated by MIKE21 are biased to have too much energy compared to SWAN simulations. Comparisons between two dissipation formulations in SWAN suggest that the Westhuysen spectra have more energy in the forward spectral than those simulated with the Komen formulation. Although the latter under - estimates the spectral peak, the spectral forward face $\left(f<f_{p}\right)$ and rear face $\left(f>f_{p}\right.$, below the equilibrium range $\left.\sim 1.5 f_{p}\right)$ are in good agreement with field observations. The lower panel of Fig. 9 compares model simulations and data after the peak of the storm is past and the wave energy is decreasing, at 06:00 on 05 August 1991 06:00. This result not only shows that MIKE21 over-estimates the spectral peak whereas SWAN (with Westhuysen form) under-estimates the spectral peak, but suggests that MIKE21's estimate for $f_{p}$ is biased too low and thus corresponding estimates for Tp and Hs are too high, as shown in Fig. 8, after the storm peak.

5.3 MEDS265 (33 m water depth) during the 1987 storm 
Data for the 1987 storm is available at the MEDS265 station which is an offshore station in water of depth $33 \mathrm{~m}$. Fig. 10 and Table 6 show the comparisons between calculated and observed values of Hs and Tp. Although the models underestimate the observed $\mathrm{Hs}$ and $\mathrm{Tp}$ values, simulations of $\mathrm{Hs}$ are in relatively better agreement with field observations than those of Tp. Model results during the peak of the storm are essentially the same for SWAN and MIKE21 simulations. Only at the beginning of the test period does MIKE21 show results that are slightly better than those of the SWAN simulations compared to observed data. Statistical analysis in Table 6 also suggests that the RMSE and SI values of MIKE21 simulations are smaller than those of the SWAN simulations.

\section{Table 6}

Statistical results for wave parameters at MEDS265 during the 1987 storm.

\begin{tabular}{llllllll}
\hline & & $\overline{x_{c}}$ & $\overline{x_{o}}$ & BIAS & RMSE & SI & $\mathrm{R}$ \\
\hline Hs (m) & SWAN (Komen) & 1.605 & 2.038 & -0.433 & 0.501 & 0.28 & 0.97 \\
& SWAN (Westhuysen) & 1.607 & 2.038 & -0.431 & 0.494 & 0.27 & 0.97 \\
& MIKE21 & 1.76 & 2.038 & -0.278 & 0.412 & 0.22 & 0.96 \\
\multirow{3}{*}{ Tp (sec) } & SWAN (Komen) & 5.244 & 7.337 & -2.094 & 2.174 & 0.35 & 0.94 \\
& SWAN (Westhuysen) & 5.737 & 7.337 & -1.60 & 1.662 & 0.26 & 0.97 \\
& MIKE21 & 6.3 & 7.337 & -1.043 & 1.389 & 0.2 & 0.91
\end{tabular}

Spectral comparisons during the 1987 storm are shown in Fig. 11. MIKE21 simulations of low initial wave energy spectra are in somewhat agreement with field observations and manage to capture the peak period $f_{p}$ (lower panel of Fig. 10) at the beginning of the computation time. However, the SWAN simulations substantially underestimate the 1-D spectrum and notably bias $f_{p}$ too low, as shown in Fig. 11 (top panel). In the case of energy spectra near the peak of the storm (middle and bottom panels of Fig. 11) the MIKE21 simulations yields better estimates of peak variance and $f_{p}$ compared to the SWAN simulations. The Westhuysen formulation in SWAN does give better results than those of the Komen formulation. In any case, the overall spectra from the MIKE21 and SWAN simulations are biased toward high frequencies, compared to field 
measurements. The differences in these simulations are reflective of the dissipative formulations used in these models, as described in Section 3.2.

5.4 BMH04 (33 m water depth) during the 2004 storm

The model simulations for this 2004 storm include extended time periods before the actual storm in order to examine the model results when spectral wave energies are low. Simulations are performed for 15 days (03 August 2004 to 17 August 2004) and compared with field measurements at BMH04, as shown in Fig. 12 and Table 7. All model simulations (SWAN and MIKE21) compare well in comparisons with field data, for both Hs and Tp. Although results are relatively good, they are not as good as the other storm cases. In particular, the $\mathrm{R}$ values are not as good as those of the 1987 storm results at MEDS265. This is also reflected by the spectra.

\section{Table 7}

Statistical results for wave parameters at BMH04 during 2004 simulations.

\begin{tabular}{llllllll}
\hline & & $\overline{x_{c}}$ & $\overline{x_{0}}$ & BIAS & RMSE & SI & R \\
\hline Hs (m) & SWAN (Komen) & 0.569 & 0.575 & -0.005 & 0.270 & 0.47 & 0.91 \\
& SWAN (Westhuysen) & 0.558 & 0.575 & -0.016 & 0.277 & 0.49 & 0.91 \\
& MIKE21 & 0.497 & 0.575 & -0.078 & 0.287 & 0.54 & 0.91 \\
\multirow{3}{*}{ Tp (m) } & SWAN (Komen) & 3.24 & 4.02 & -0.78 & 1.211 & 0.34 & 0.84 \\
& SWAN (Westhuysen) & 3.496 & 4.020 & -0.523 & 0.989 & 0.26 & 0.87 \\
& MIKE21 & 3.316 & 4.020 & -0.703 & 1.323 & 0.36 & 0.80 \\
\hline
\end{tabular}

Overall, the Hs time series (top panel of Fig. 12) for MIKE21 and SWAN simulations are in good agreement with field data except at the peak of the storm when the MIKE21 simulation is biased low whereas the SWAN simulations are closer to observations. These trends are also evident in statistical variables in Table 7. Although the correlation coefficients are essentially the same for the model simulations of Hs, results from the MIKE21 simulation show slightly higher RMSE and SI. Associated results for Tp are given 
in the lower panel of Fig. 12. Both MIKE21 and SWAN simulations under-estimate Tp during the storm peak. The SWAN simulation using the Westhuysen dissipative formulation is in better agreement with field observations compared to results from the MIKE21 simulation or the SWAN simulation using the Komen formulation. Comparisons between the latter two simulations suggest that the MIKE21 simulation is in better agreement with field observations of $\mathrm{Tp}$.

Two comparisons between computed and measured spectra at BMH04 are shown in Fig. 13, corresponding to examples of low spectral energy before the arrival of the storm, and also high spectral energy during the peak of the storm. Although the low energy spectrum (top panel of Fig. 13) is well predicted by both MIKE21 and SWAN simulations, the SWAN simulations of the spectral distribution are in better agreement with measurements. The SWAN simulation using the Westhuysen formulation results in a spectral distribution that is biased toward lower frequencies compared to SWAN results obtained using the Komen formulation. By comparison, the MIKE21 simulation of the spectra is biased toward high frequencies compared to both SWAN simulations. These results are repeated in comparisons of the spectral energy (bottom panel of Fig. 13) at the peak of the storm. Again, the spectrum from the MIKE21 simulation is substantially biased toward high frequency, which yields lower Tp values during the peak of the storm (Fig. 12), whereas spectra from the SWAN simulations are in better agreement with field data.

\section{CONCLUSIONS}

This study investigates model sensitivity of two spectral wave models, SWAN and MIKE21, in simulating storm-generated wave conditions in the southern Beaufort Sea particularly in the Mackenzie Delta region and adjacent coastal waters. Modelled wave parameters and variance spectra are compared with field observations during four storms at four in situ stations.

In the case of nearshore shallow water observations, SWAN and MIKE21 simulations are close. At the very shallowest location, the SWAN simulation with the Westhuysen formulation tends to provide the best simulation of Hs, whereas the MIKE21 
simulation tends to be slightly better in estimating Tp than the SWAN (Westhuysen) simulation. Associated comparisons of variance spectra suggest that although all simulations are competitive in their skill, the MIKE21 simulation tends to overestimate the spectral peak whereas the SWAN simulations tends to underestimate the peak.

Tests involving deep water observations suggest that the models are better able to simulate Hs than Tp. Although their overall accuracies in predicting Hs and Tp by MIKE21 and SWAN are close, the SWAN simulations of Hs and Tp during the peak of the storm are better than those of the MIKE21 simulation. However, the SWAN model gives a larger bias than MIKE21 in the case of the 1987 storm simulation at MEDS265, whereas SWAN model results give higher correlation with the measured values. In terms of the variance spectra, the MIKE21 simulations are similar to the SWAN simulations, particularly when the Westhuysen dissipative formulation is used. All three simulation schemes show the similar correlations to observations in predicting Hs; however, SWAN with the Westhuysen formulation exhibits a higher correlation for Tp followed by the Komen and Mike 21 simulations. This result is consistent with the suggestion by Van der Westhuysen et al. [16] that improved simulations of Tp would follow from a saturation-based whitecapping parameterization in the SWAN model.

Although model simulations are essentially in good agreement with field measurements, the findings of model simulations are found to be case-specific and model skill varies with storm intensity and spatial location in the study area. Differences in models' skills are also due to parameterizations used in the models, differences in numerical schemes, and discretization options, as described in Section 3. A more comprehensive discussion on these aspects is given by Perrie et al. [44], where three modern operational wave forecast model systems are implemented on fine-resolution grids for the Northwest Atlantic, based on SWAN and WAVEWATCHIII® wave models, and tested with three intense mid latitude nor'easters. Here, in this study, model sensitivity analyses suggest that overall, the SWAN simulations with the Westhuysen dissipative formulation tends to give the better results than the SWAN with the Komen dissipative formulation, or MIKE21 simulations. This is based on an overall assessment of the time series of Hs and Tp in Figures 6, 8, 10 and 12, and especially the performance of the 
models at the peaks of the storms, as shown in Figures 7, 9, 11 and 13. Results are also summarized in Tables 4-7.

\section{ACKNOWLEDGEMENT}

This article is Geological Survey of Canada Contribution and support for this research was from the Canadian Panel on Energy Research and Development (PERD-Offshore Environmental Factors and Northern Programs), and the Canadian Federal IPY Office. This work was also supported by the Office of Naval Research, Code 322, "Arctic and Global Prediction", directed by Dr. Martin Jeffries and Scott Harper (Grant number and Principal Investigator: William Perrie, N00014-15-1-2611).

\section{REFERENCES}

[1] Wang, Xiaolan L.; Feng, Yang; Swail, Val R.; and Cox, Andrew; 2015: Historical Changes in the Beaufort-Chukchi-Bering Seas Surface Winds and Waves, 19712013. J. Climate, 28, 7457-7469. doi: http://dx.doi.org/10.1175/JCLI-D-15-0190.1

[2] Khon VC, Mokhov II, Pogerskiy FA, Babanin A, Dethloff K, Rinke A, Matthes H. Wave heights in the $21^{\text {st }}$ century Arctic Ocean simulated with a regional climate model. Geophysical Research Letters 2014; 41:2956-2961.

[3] Hemer MA, Fan,Y, Mori N, Semedo A, Wang XL. Projected change in wave climate from a multi-modal ensemble. Nature Climate Change 2013; 3:471-476.

[4] Dobrynin M, Murawsky J, Yang S. Evolution of global wind wave climate in CMIP5 experiments. Geophysical Research Letters 2012; 39, L18606.

[5] Overeem I, Anderson RS, Wobus CW, Clow GD, Urban FE, Matell N. Sea ice loss enhances wave action at the Arctic coast. Geophysical Research Letters 2011; 38, L17503.

[6] Hudak DR, Young MC. Storm climatology of the southern Beaufort Sea. Atmosphere-Ocean 2002; 40(2):145-158.

[7] Moeini MH, Etemad-Shahidi A. Application of two numerical models for wave hindcasting in Lake Erie. Applied Ocean Research 2007; 29:137-145. 
[8] Hoque MA, Mulligan R, Perrie W, Toulany B, Zhang, L. Preliminary modelling of shallow water waves off the Mackenzie Delta. Halifax: $11^{\text {th }}$ International Workshop on Wave Hindcasting and forecasting; 2009.

[9] Hill PR, Blasco SM, Harper JR, Fissel DB. Sedimentation on the Canadian Beaufort Self. Continental Self Research 1991; 11:821-842.

[10] Solomon SM. Spatial and temporal variability of shoreline change in the BeaufortMackenzie region, Northwest Territories, Canada. Geo-marine Letters 2005; 25:127137.

[11] Manson G, Solomon SM. Past and future forcing of Beaufort Sea coastal changes. Atmosphere-Ocean 2007; 45 (2):107-122.

[12] Booij N, Ris RC, Holthuijsen LH, A third-generation wave model for coastal regions, Part I, Model description and validation. J Geophys Res 1999; 104:7649-7666.

[13] Komen GJ, Cavaleri L, Donelan M, Hasselmann K, Hasselmann S, Janssen PAEM. Dynamics and modelling of ocean waves. Cambridge: Cambridge University Press; 1994.

[14] Hasselmann K. On the spectral dissipation of ocean waves due to whitecapping. Boundary Layer Meteorology 1974; 6:107-127.

[15] Holthuijsen LH. Waves in oceanic and coastal waters. Cambridge: Cambridge University Press; 2007.

[16] Alves J, Banner M. Performance of a saturation-based dissipation-rate source term in modelling fetch-limited evolution of wind waves. J Phys Oceanogr 2003; 33:12741298.

[17] Van der Westhuysen AJ, Zijlema M, Battjes JA. Nonlinear saturation-based whitecapping dissipation in SWAN for deep and shallow water. Coastal Engineering 2007; 54(2):151-170.

[18] Ris RC, Booij N, Holthuijsen LH. A third generation wave model for coastal regions, Part II: Verification. J Geophys Res 1999; 104(C4):7667-7681.

[19] Hasselmann K, Barnett TP, Bouws E, Carlson H, Cartwright DE, Enke K, et el. Measurements of wind-wave growth and swell decay during the Joint North Sea Wave Project (JONSWAP). Dtsch Hydrogr Z Suppl 1973; 12:A8. 
[20] Collins JI. Prediction of shallow water spectra. J Geophys Res 1972; 77(15):26932707.

[21] Madsen OS, Poon YK, Graber HC. Spectral wave attenuation by bottom friction: Theory. In: Proc. $21^{\text {th }}$ International Conference on Coastal Engineering. 1988. p. 492504.

[22] Battjes JA, Janssen JPFM. Energy loss and set-up due to breaking of random waves. In: Proc. $16^{\text {th }}$ International Conference on Coastal Engineering. 1978. p. 569-587.

[23] Hasselmann S, Hasselmann K, Allender JH, Barnett TP. Computations and parameterizations of the nonlinear energy transfer in a gravity wave spectrum, Part II: Parameterizations of the nonlinear transfer for application in wave models. J Phys Oceanogr 1985; 15(11):1378-1391.

[24] Eldeberky Y (PhD Thesis) Nonlinear transformation of wave spectra in the nearshore zone. Delft University of Technology: 1996.

[25] Eldeberky Y, Battjes JA. Parameterization of triad interactions in wave energy models. In: Proc. Coastal Dynamics. 1995. p. 140-148.

[26] Holthuijsen LH, Booij N, Herbers THC. A prediction model for stationary, shortcrested waves in shallow water with ambient currents. Coastal Engr 1989; 13:23-54.

[27] Young IR. Wind-generated ocean waves. In: Bhattacharyya R, McCormic ME, Editors Ocean engineering book series, Elsevier, 1999, Volume 2.

[28] Johnson HK, Kofoed-Hansen H. Influence of bottom friction on sea surface roughness and its impact on shallow water wind wave modeling. J Phys Oceanogr 2000; 30:1743-1756.

[29] Weber SL. Bottom Friction for Wind Sea and swale in extreme depth limited situation, J Phys Oceangr 1991; 10:1712-1733.

[30] Johnson IG, Carlsen NA. Experimental and theoretical investigations in an oscillatory turbulent boundary layer. J Hydraul Res 1976; 14:45-60.

[31] Holthuijsen LH, Booij N, Bertotti L. The propagation of wind errors through ocean wave hindcasts. J Offshore Mech Arct Eng 1996; 118:184-189.

[32] Ponce de León S, Ocampo-Torres FJ. Sensitivity of a wave model to wind variability. Journal of Geophysical Research 1998; 103(C2):3179-3201. 
[33] Ponce de León S, Sánchez-Arcilla A. Sensitivity of a wave model to wind input in the Catalan Coast. In: Proc. International Conference on the Wind and Wave Climate of the Mediterranean and Black Sea. 1999.

[34] Ponce de León S, Guedes Soares C. Sensitivity of wave model predictions to wind field in the western Mediterranean Sea. Coastal Engineering 2008; 55:920-929.

[35] Teixeira JC, Abreu MP, Guedes Soares C. Uncertainty of ocean wave hindcast due to wind modeling. J Offshore Mech Arct Eng 1995; 117:294-297.

[36] Murray MA, Maes M. Beaufort Sea extremal wave studies assessments. Report Series No. 023. Ottawa, Canada: Environmental Studies Revolving Fund; 1986.

[37] Swail VR, Cardone VJ, Ferguson M, Gummer DJ, Cox AT. MSC Beaufort Sea wind and wave reanalysis. In: 10 ${ }^{\text {th }}$ International Wind and Wave Workshop. 2007.

[38] Squire VA. Numerical modeling of realistic ice floes in ocean waves. Ann Glaciol $1983 ; 4: 277-282$.

[39] Eid BM, Cardone VJ. Beaufort Sea extreme waves study. Report Series No. 114. Calgary, Canada: Environmental Studies Research Funds; 1992.

[40] Perrie W, Hu Y. Air-ice--ocean momentum exchange, Part I: Energy transfer between waves and ice floes. J Phys Oceanogr 1996; 26:1705-1720.

[41] Perrie W, Hu Y. Air-ice-ocean momentum exchange, Part II: Ice Drift. J Phys Oceanogr 1997; 27:1976-1996.

[42] Henry RF, Foreman MGG. Numerical model studies of semi-diurnal tides in the southern Beaufort Sea. In: Pacific Marine Science Report No. 77-11. British Columbia, Canada: Department of Fisheries and Oceans Canada; 1977.

[43] Komen GJ, Hasselmann S, Hasselmann K. On the existence of a fully developed wind-sea spectrum. J Phys Oceanogr 1984; 14:1271-1285.

[44] Perrie, W., B. Toulany, A. Roland, M. Dutour-Sikiric, C. S. Chen, R. C. Beardsley, J. Qi, Y. Hu: 2016: Modelling North Atlantic Nor'easters with Modern Wave Forecast Models. Under review, J. Geophys. Res. 


\section{Figure Captions}

Fig. 1. Study area.

Fig. 2. Computational domains used in SWAN simulations. Locations of wave observation stations are shown.

Fig. 3. Computational domain and unstructured grids used in MIKE 21simulations.

Fig. 4. Wind speeds and directions during the four storm events, comparing MSCB modelled data with field measurements at Tuktoyaktuk $\left(133^{\circ} \mathrm{W}, 69.45^{\circ} \mathrm{N}\right)$. Wind directions are from the north. Times indicated during different storm events are UTC.

Fig. 5. Ice cover during the storms in 1985 and 1991.

Fig. 6. Comparisons of modelled and measured $\mathrm{Hs}$ and $\mathrm{Tp}$ in $2.24 \mathrm{~m}$ water depth at WELL116 during the 1985 storm.

Fig. 7. Comparisons of variance spectra at WELL116 at the peak of the 1985 storm.

Fig.8. Comparisons of modelled and measured Hs and Tp in $7 \mathrm{~m}$ water depth at MEDS291 during the 1991 storm.

Fig. 9. Comparisons of variance spectra at MEDS 291 at the peak of the 1991 storm.

Fig. 10. Comparisons of modelled and measured Hs and Tp in $33 \mathrm{~m}$ water depth at MEDS265 during the 1987 storm.

Fig. 11. Comparisons of variance spectra at MEDS265 during the 1987 storm.

Fig. 12. Comparisons of modelled and measured $\mathrm{Hs}$ and Tp in $33 \mathrm{~m}$ water depth at BMH04 during the 2004 storm.

Fig. 13. Comparisons of variance spectra at BMH04 at during the 2004 storm. 


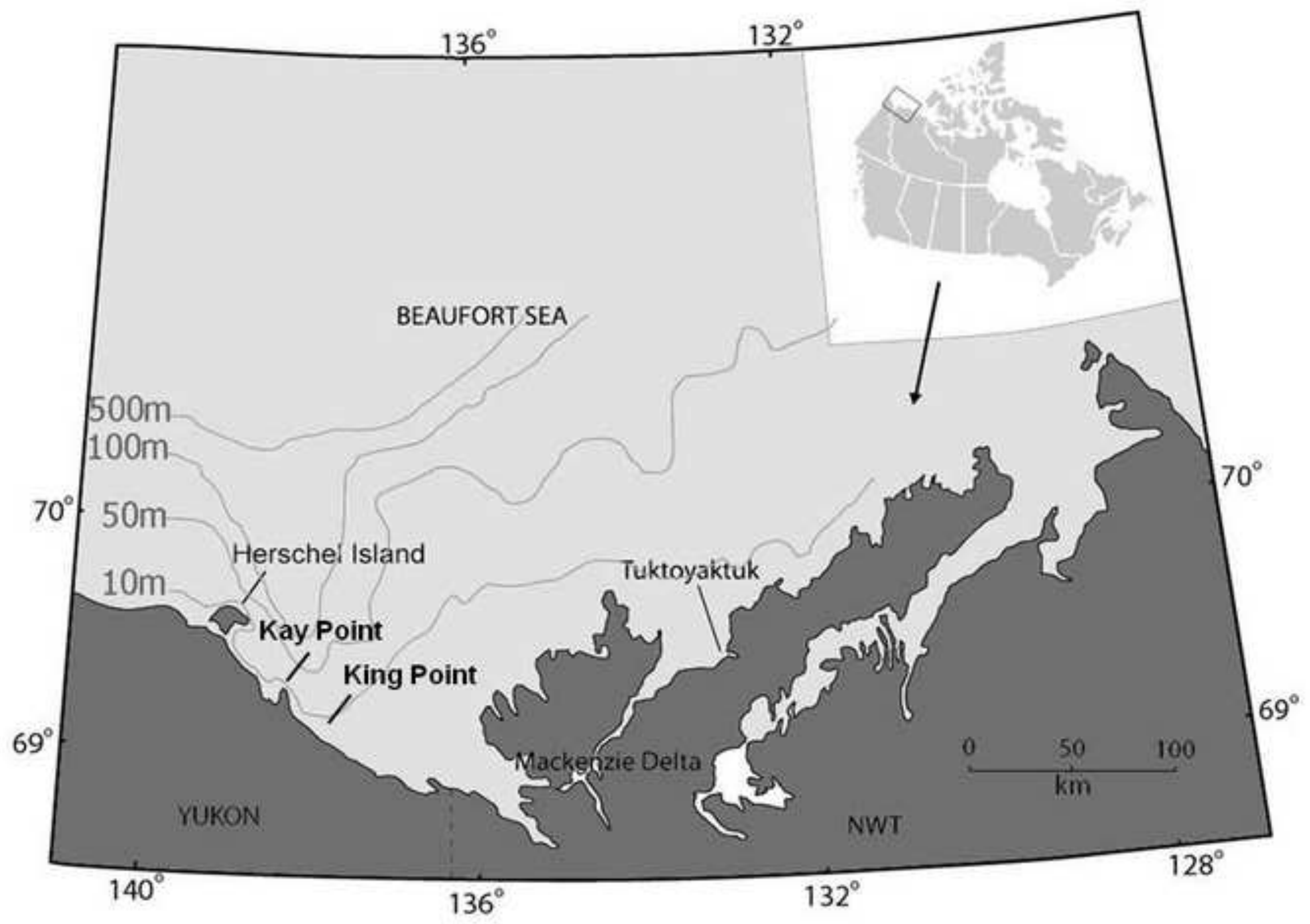




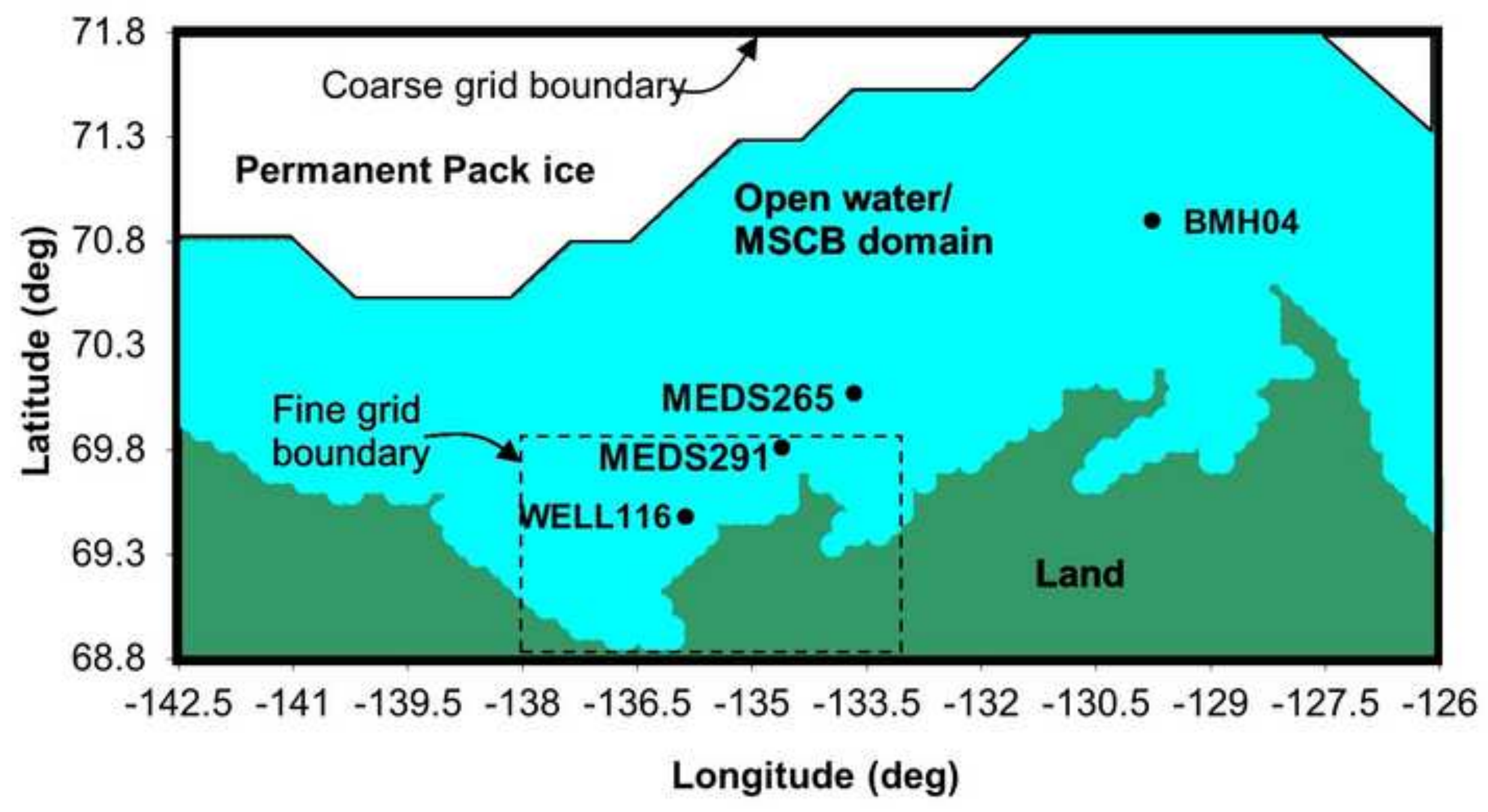



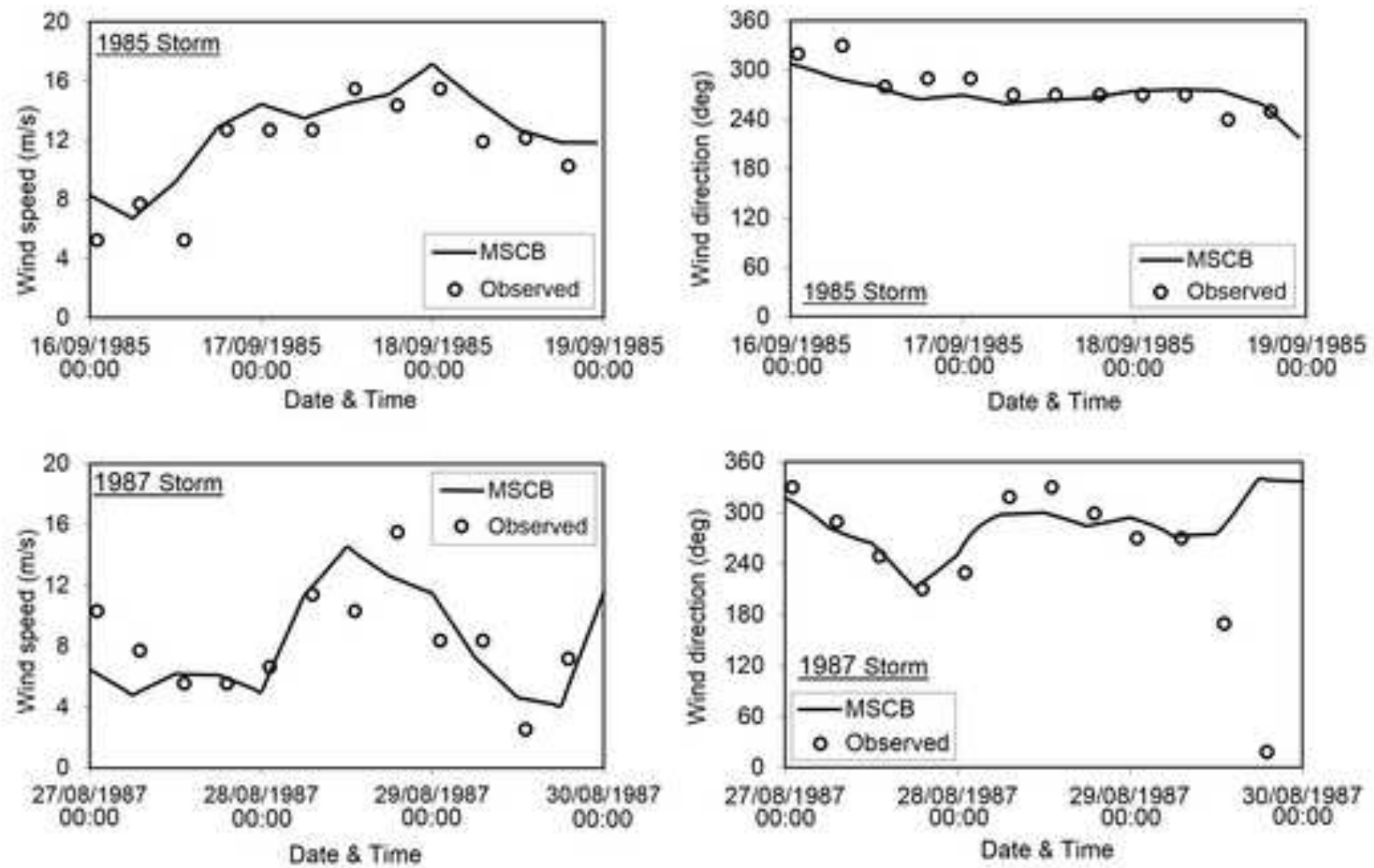

Date \& Time
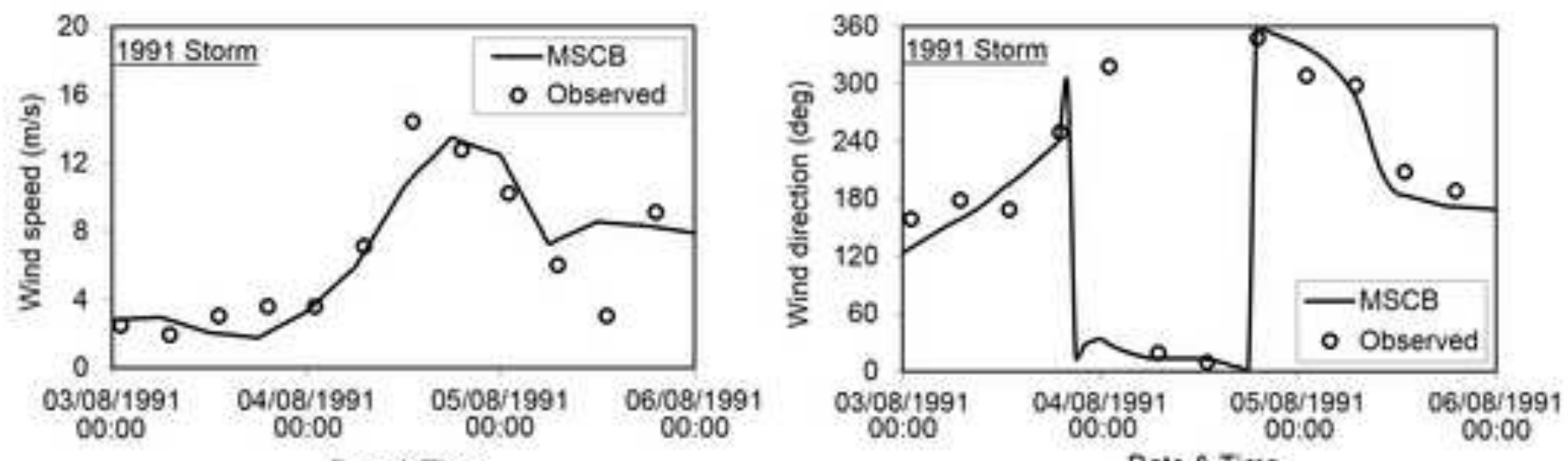

Date \& Time

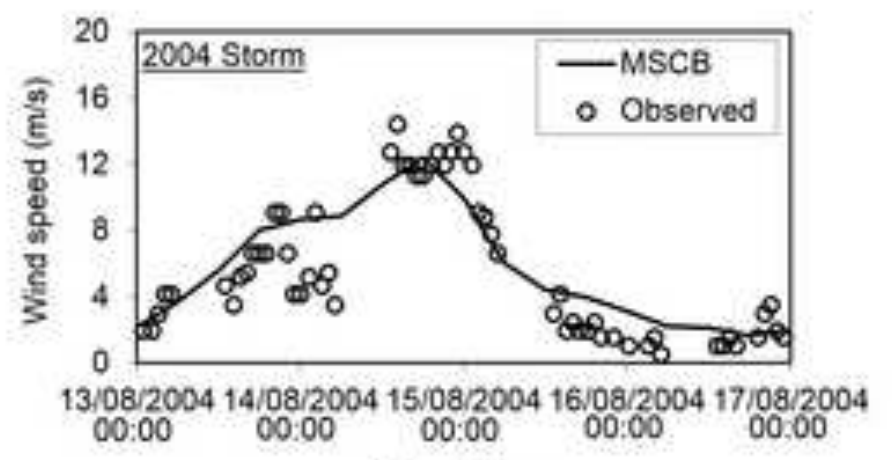

Date \& Time

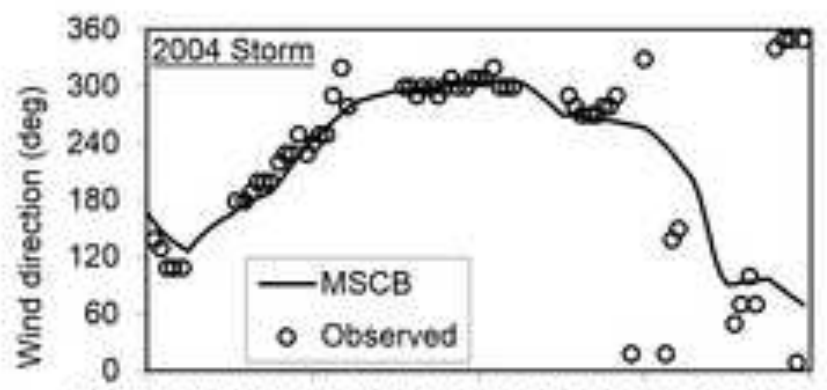
$\begin{array}{ccccc}13 / 08 / 2004 & 14 / 08 / 2004 & 15 / 08 / 2004 & 16 / 08 / 2004 & 17 / 08 / 2004 \\ 00,00 & 00: 00 & 00.00 & 00: 00 & 00.00\end{array}$

Date \& Time 

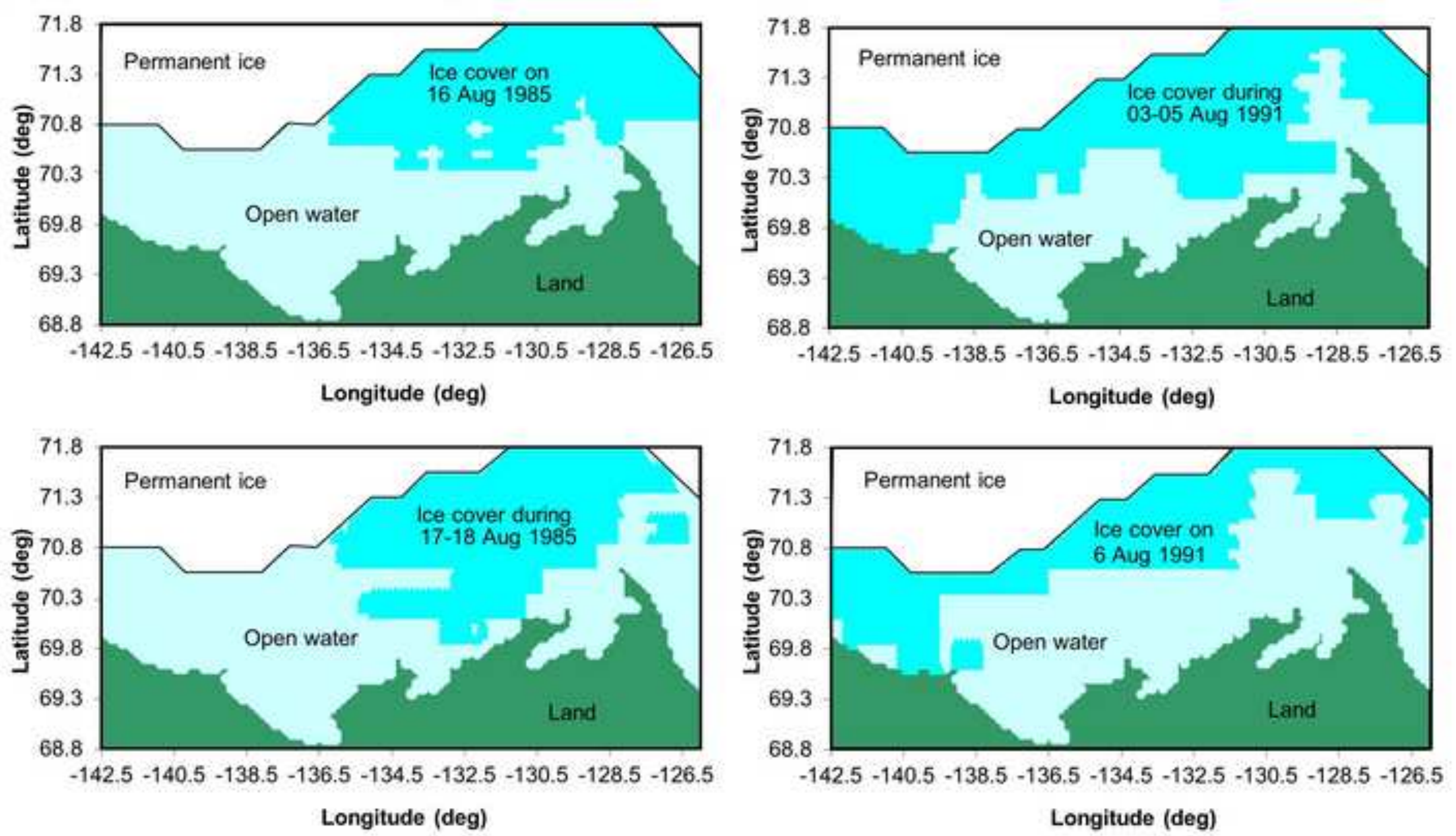

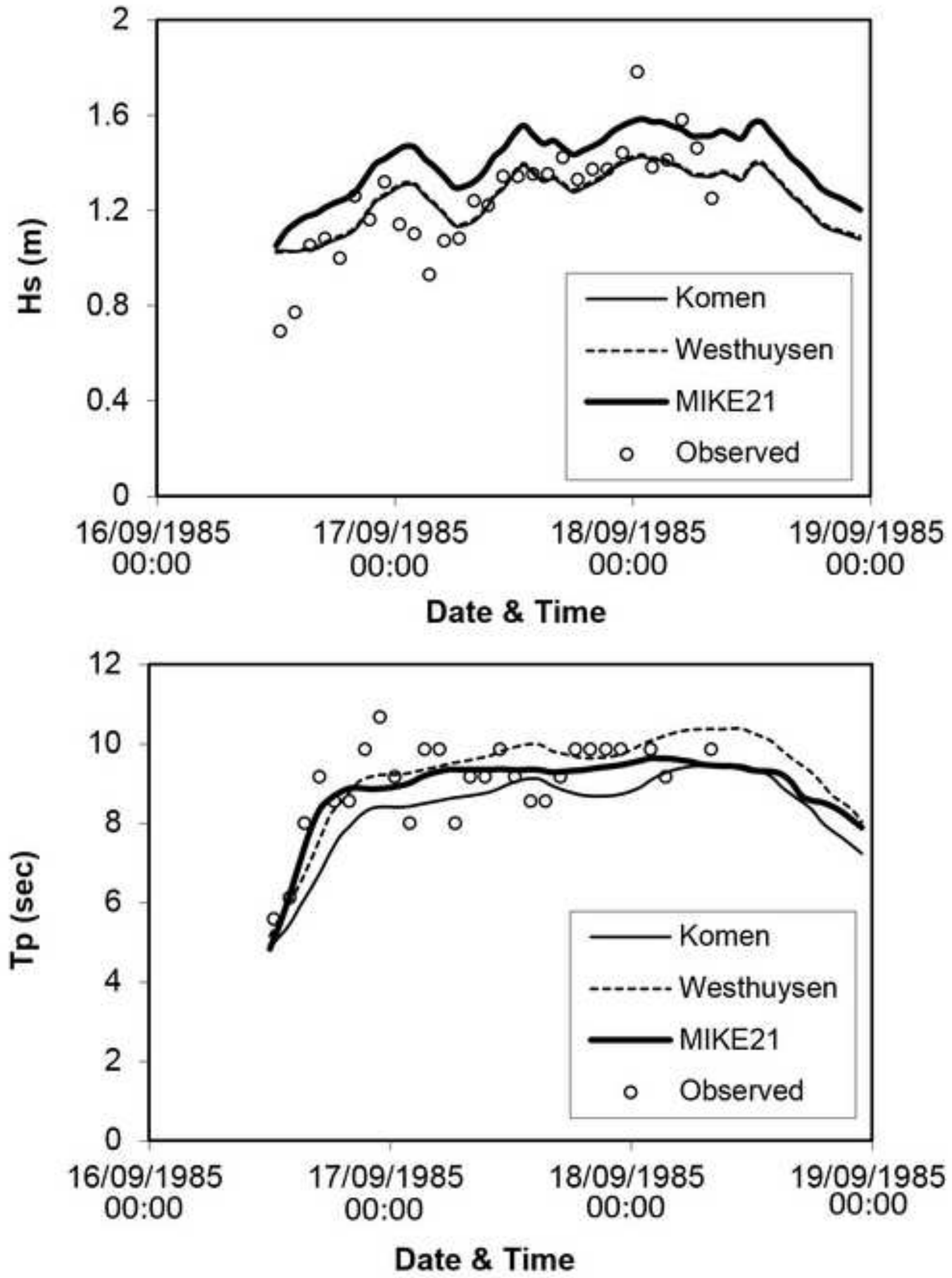

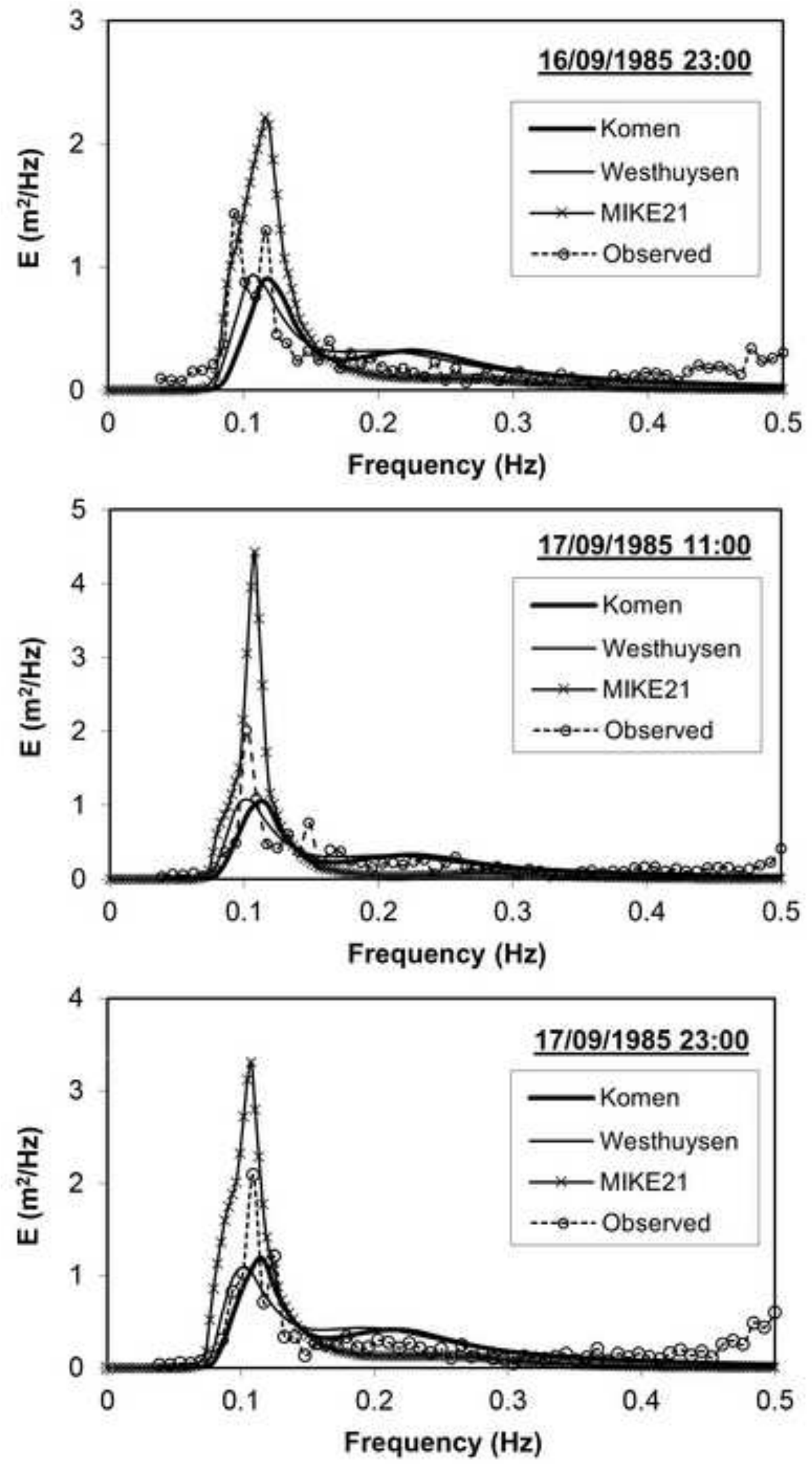


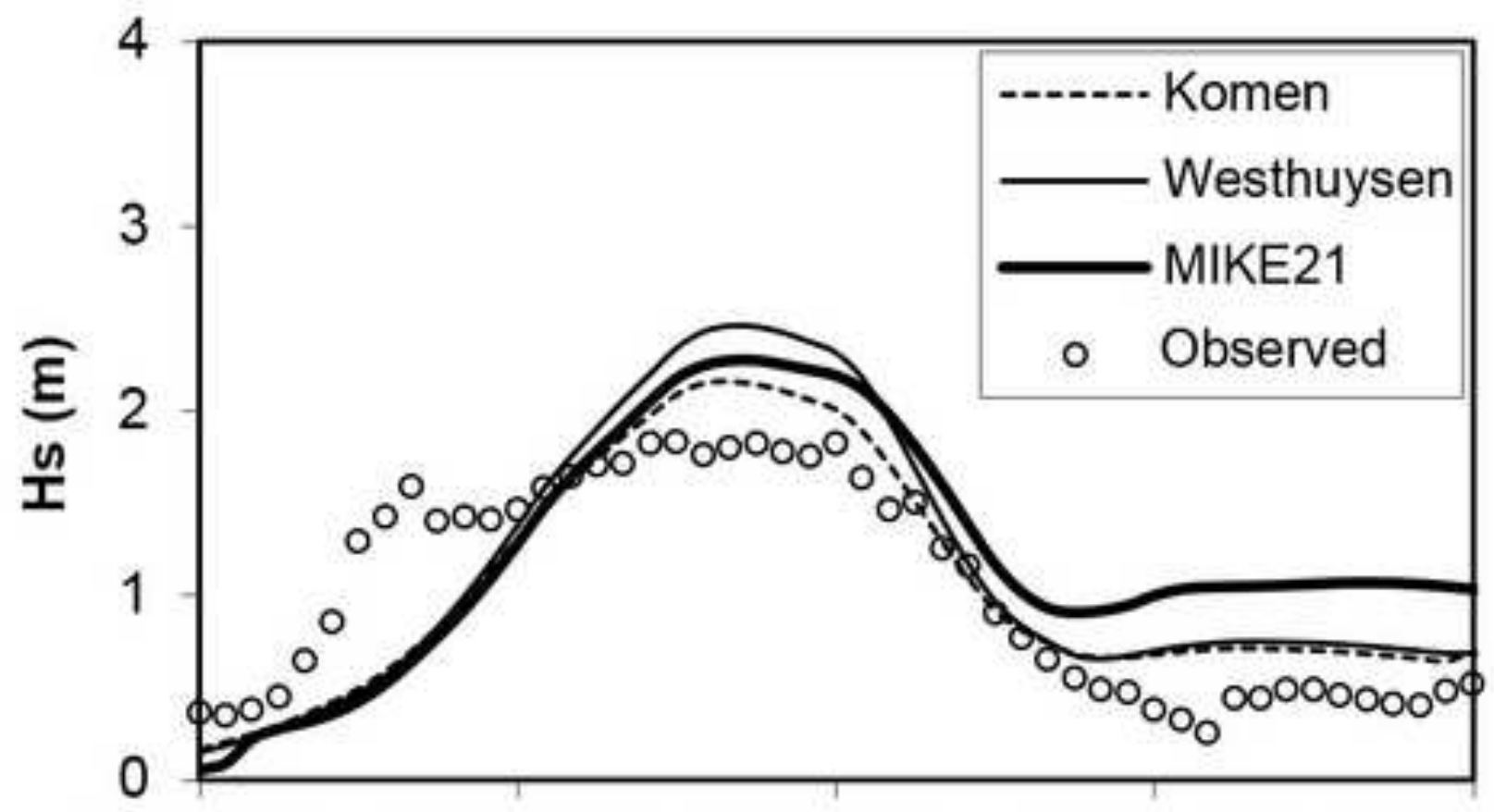

04/08/1991 04/08/1991 05/08/1991 05/08/1991 06/08/1991 00:00 $00: 00$ 00:00 00:00 00:00

Date \& Time

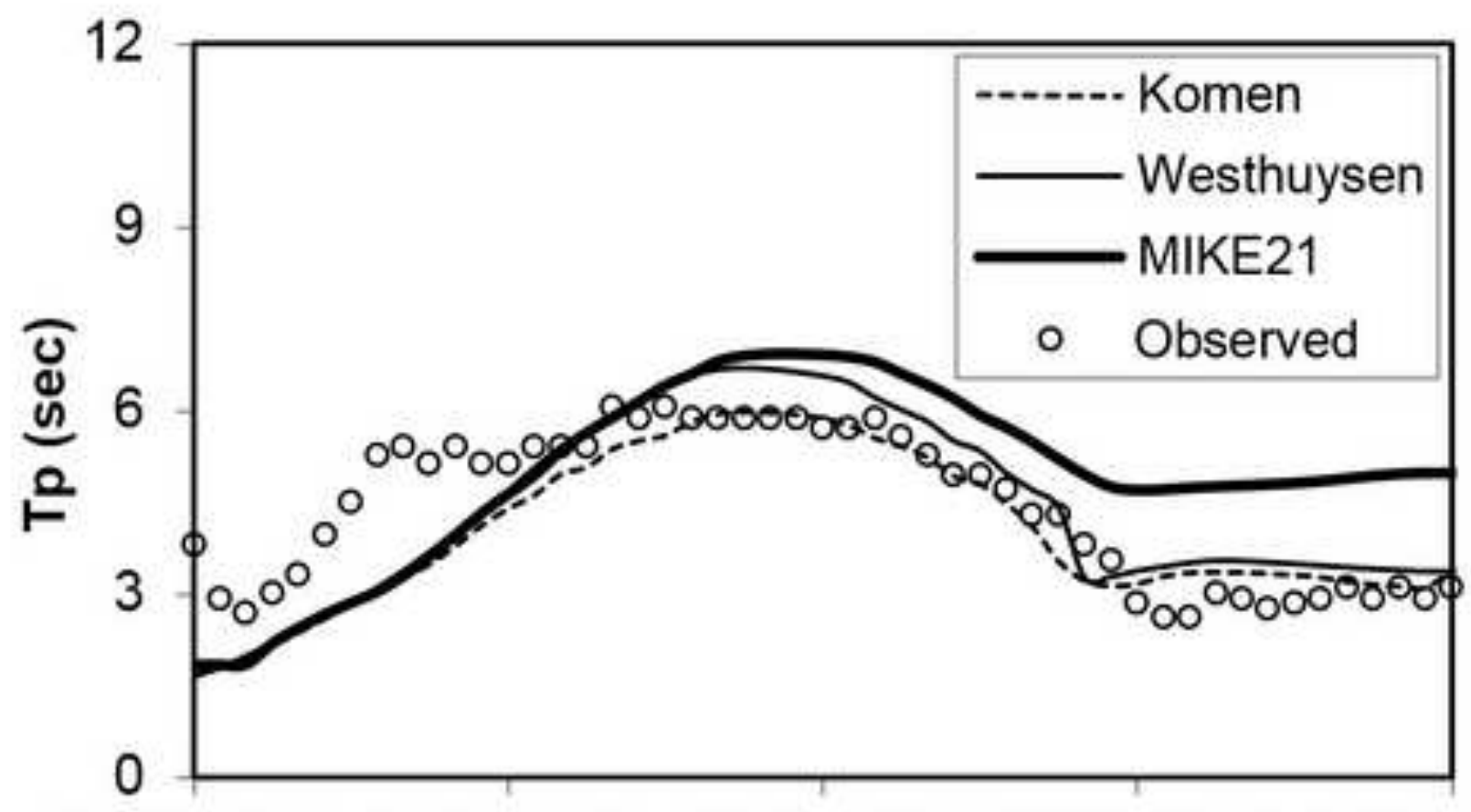

04/08/1991 04/08/1991 05/08/1991 05/08/1991 06/08/1991 00:00 00:00 00:00 00:00 00:00 

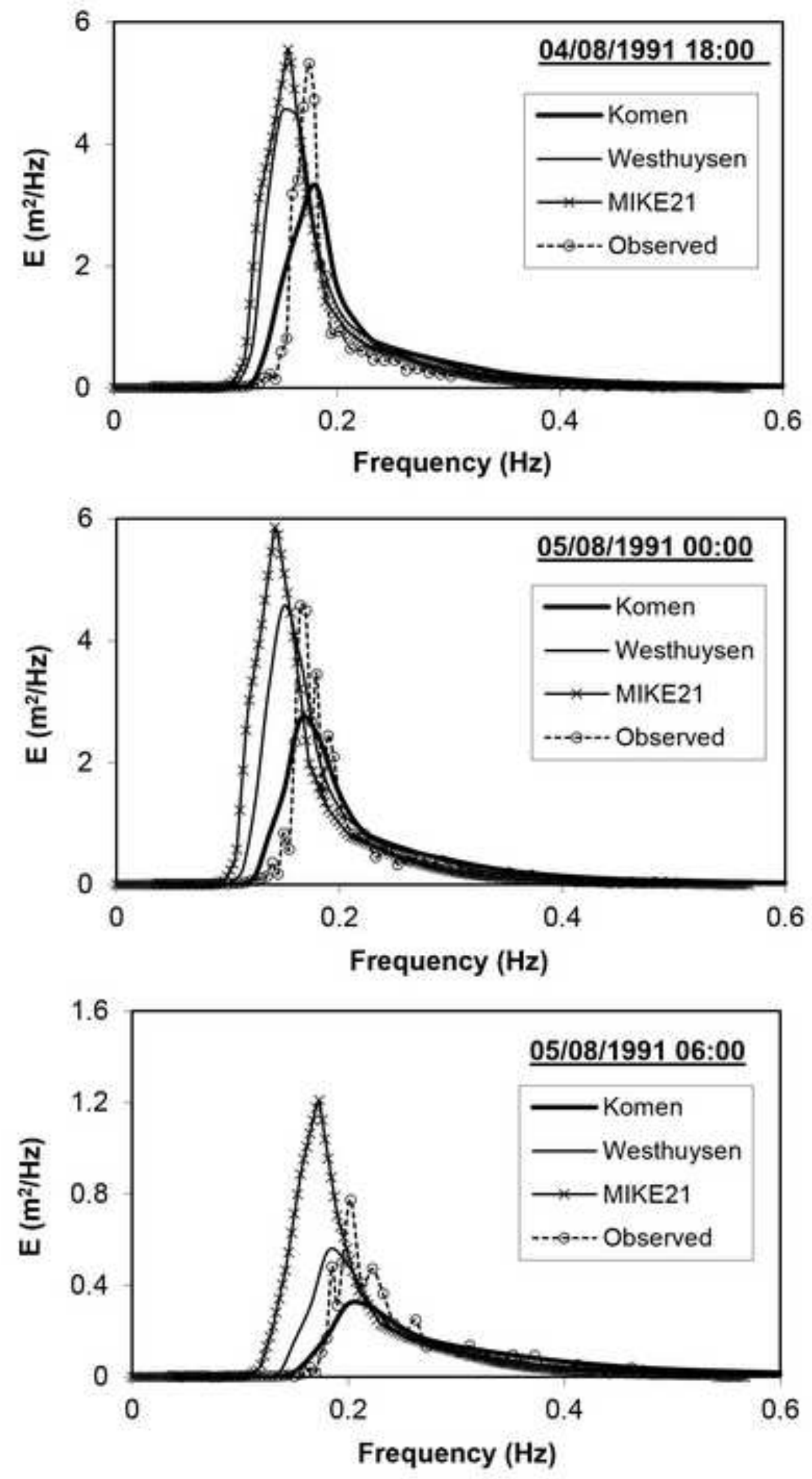

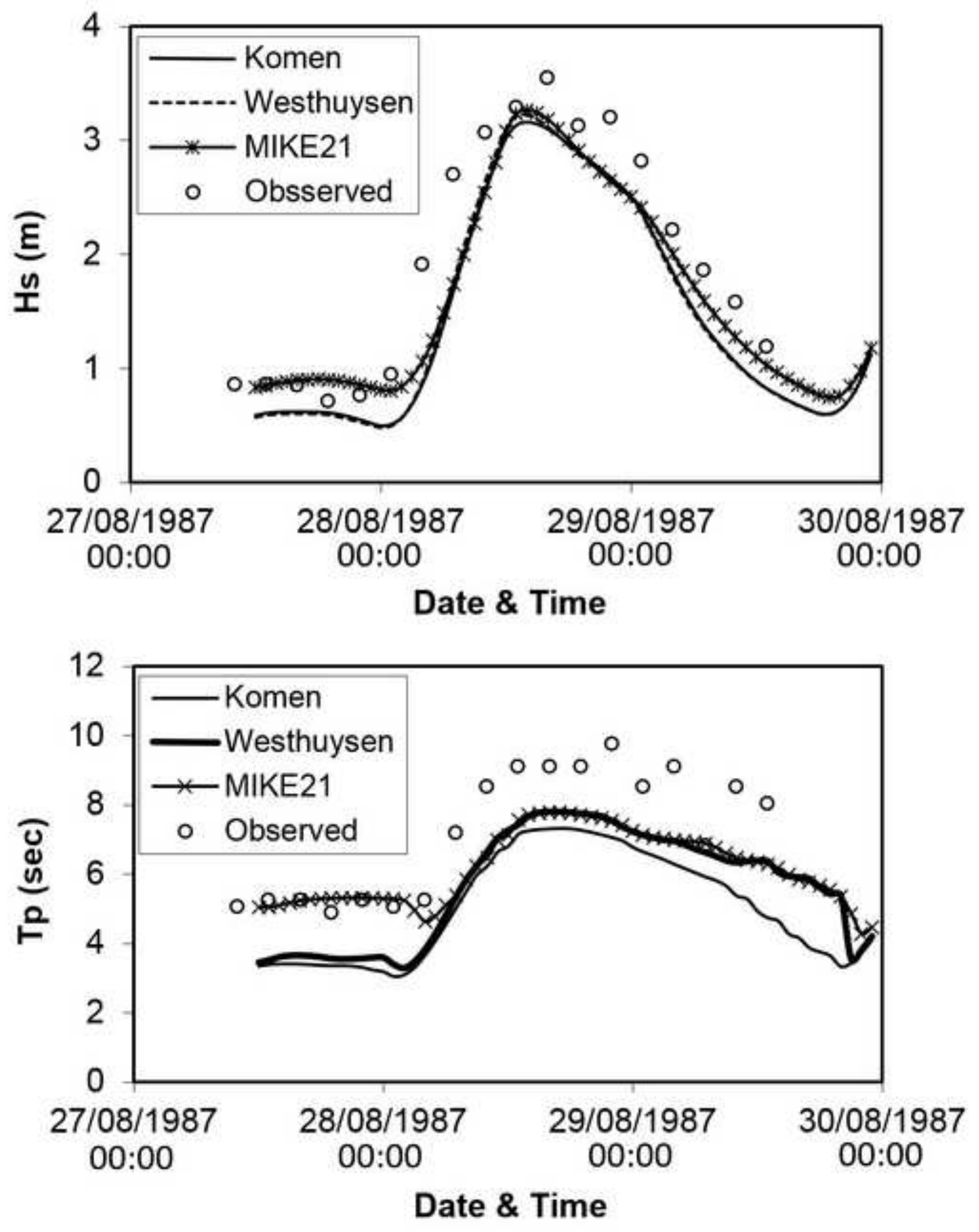

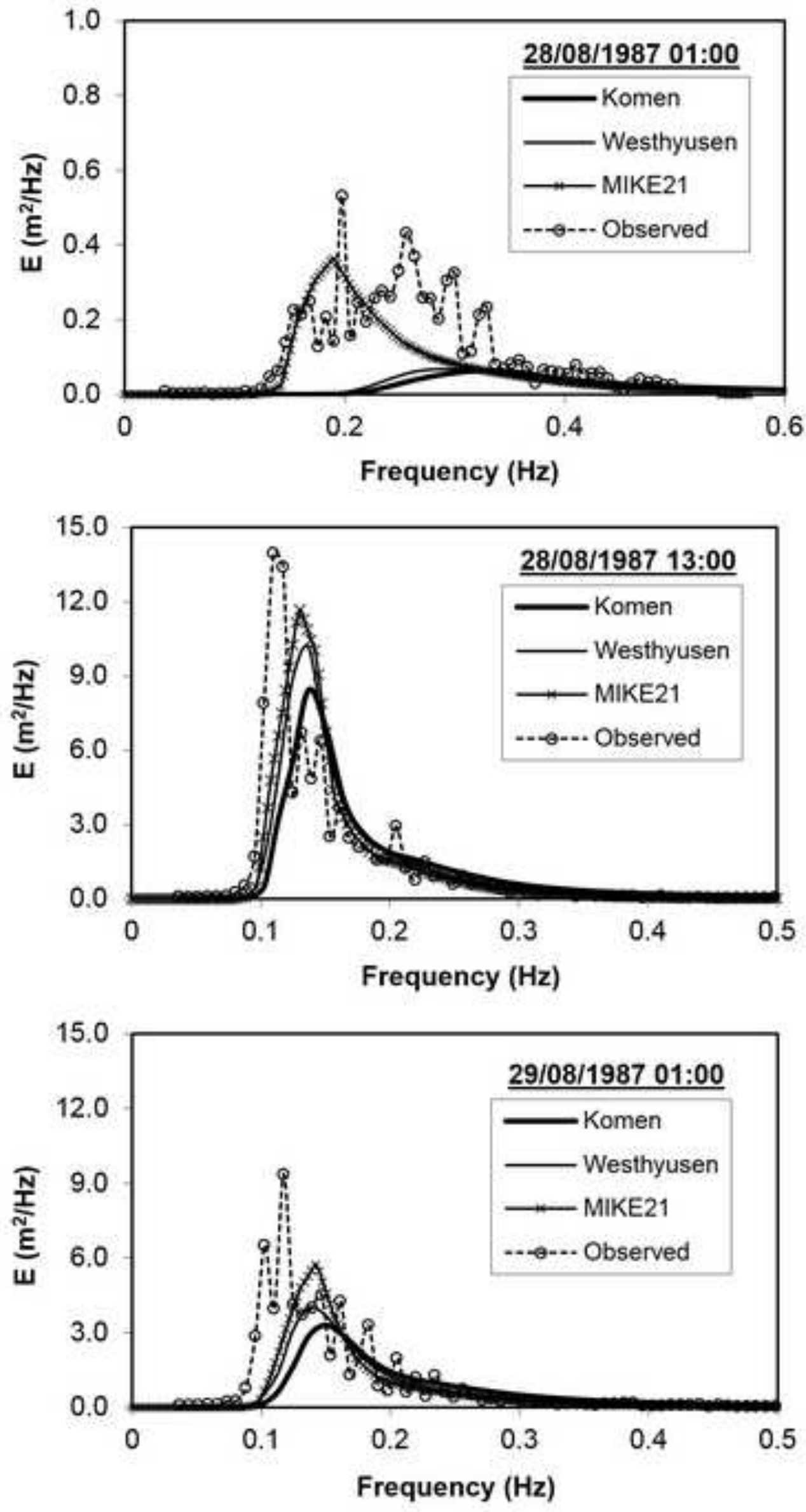

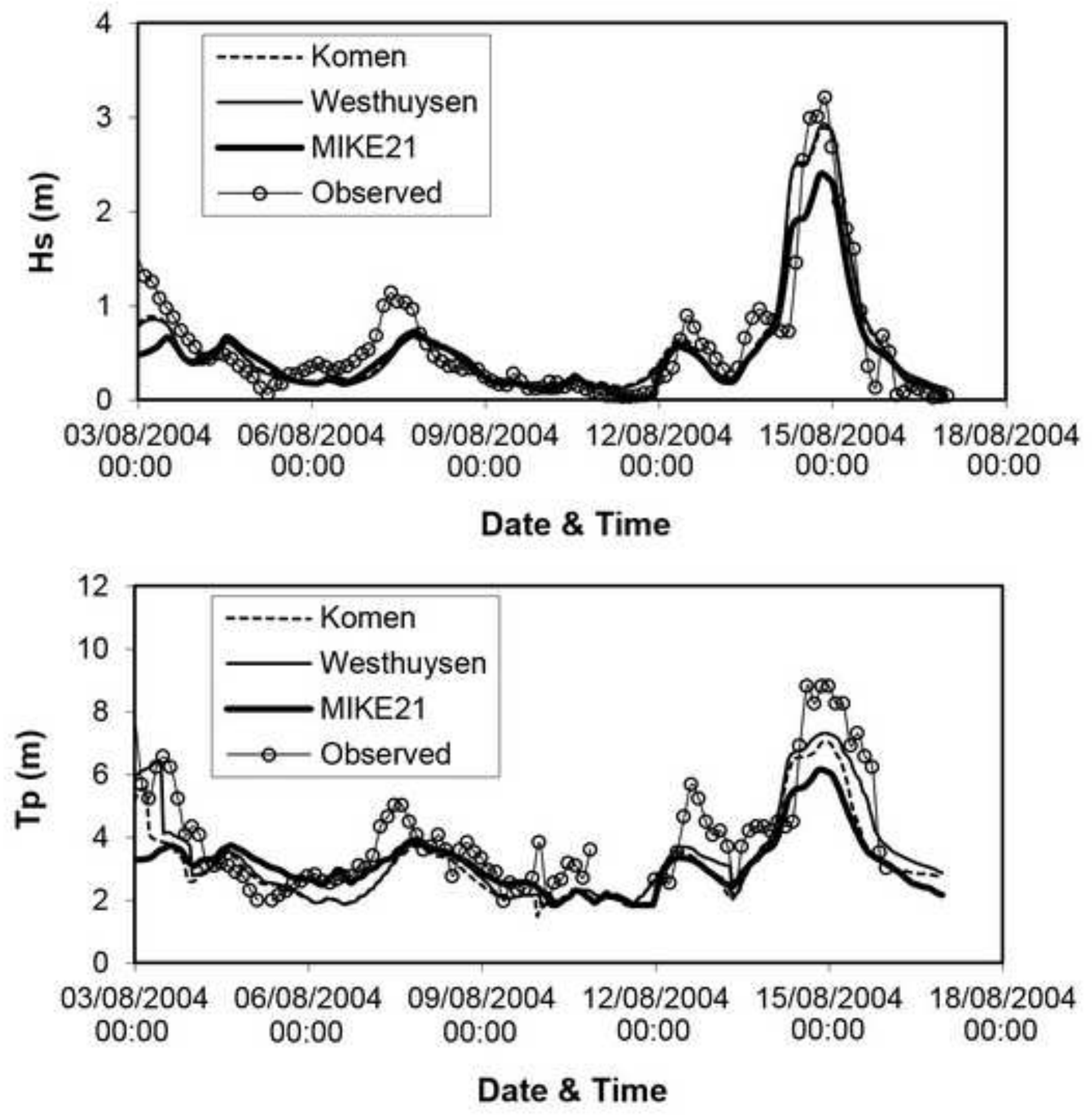

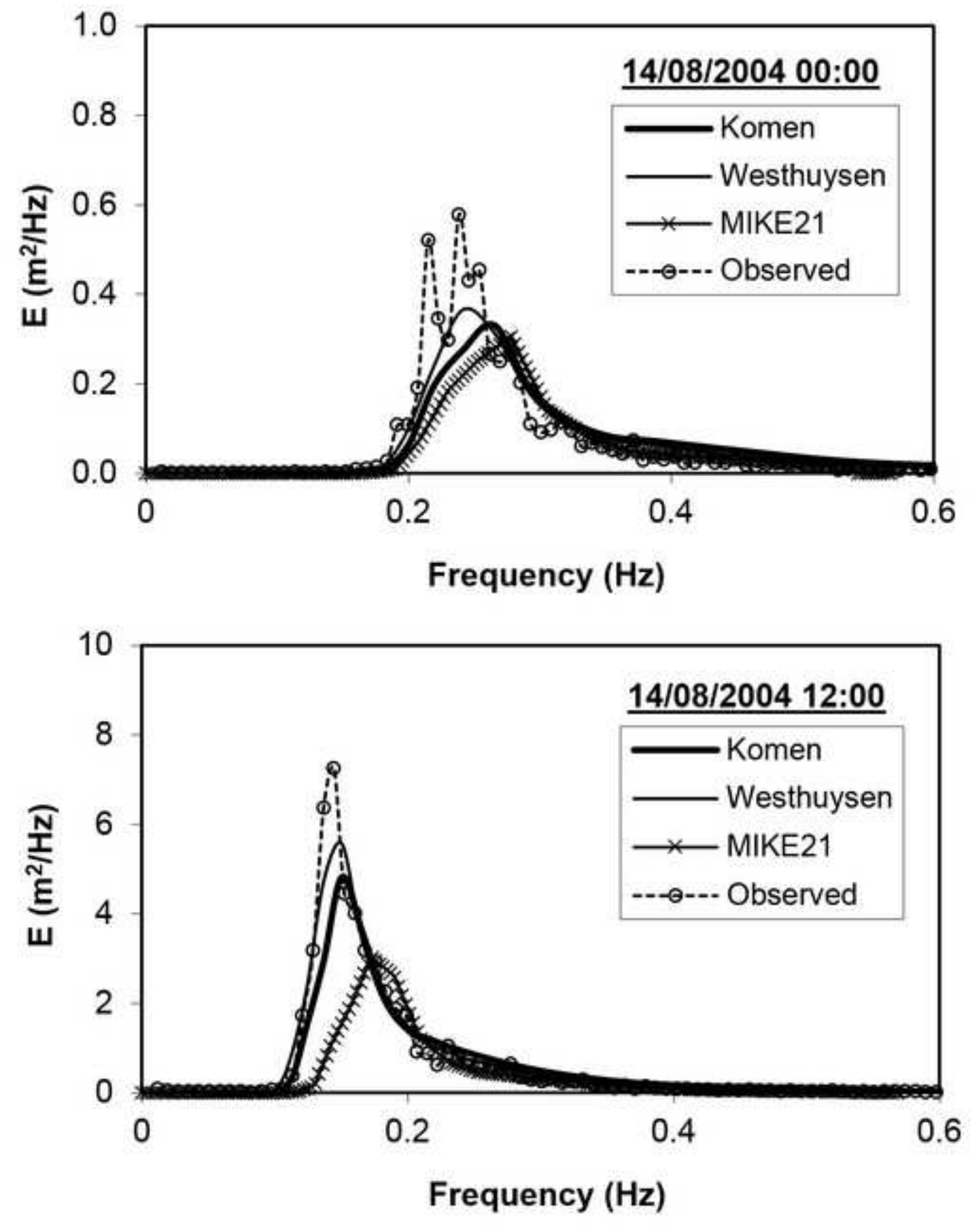

Figure-13 